UNIVERSIDADE DE SÃO PAULO

FACULDADE DE ECONOMIA, ADMINISTRAÇÃO E CONTABILIDADE

DEPARTAMENTO DE ECONOMIA

PROGRAMA DE PÓS-GRADUAÇÃO EM ECONOMIA

A DESIGUALDADE DE RENDA NO BRASIL ESTÁ REALMENTE DECLINANDO? UMA ABORDAGEM CONSIDERANDO O PROBLEMA DE SELEÇÃO

Aluno: Andre Marinho da Silva

Professor Dr. Naércio Aquino Menezes-Filho

SÃO PAULO

2009 
Profa. Dra. Suely Vilela

Reitora da Universidade de São Paulo

Prof. Dr. Carlos Roberto Azzoni

Diretor da Faculdade de Economia, Administração e Contabilidade

Prof. Dr. Joaquim José Martins Guilhoto

Chefe do Departamento de Economia

Prof. Dr. Dante Mendes Aldrighi

Coordenador do Programa de Pós-Graduação em Economia 


\section{A DESIGUALDADE DE RENDA NO BRASIL ESTÁ REALMENTE DECLINANDO? UMA ABORDAGEM CONSIDERANDO O PROBLEMA DE SELEÇÃO}

Dissertação apresentada ao Departamento de Economia da Faculdade de Economia, Administração e Contabilidade da Universidade de São Paulo como requisito para a obtenção do título de Mestre em Economia

Professor Dr. Naércio Aquino Menezes-Filho

\section{SÃO PAULO}




\section{FICHA CATALOGRÁFICA}

Elaborada pela Seção de Processamento Técnico do SBD/FEA/USP

Silva, Andre Marinho da

A desigualdade de renda no Brasil está realmente declinando ? uma abordagem considerando o problema de seleção / Andre Marinho da Silva. - São Paulo, 2009.

$50 \mathrm{p}$.

Dissertação (Mestrado) - Universidade de São Paulo, 2009 Bibliografia.

1. Distribuição de renda 2. Desigualdade de renda 3. Econometria I. Universidade de São Paulo.Faculdade de Economia, Administração e Contabilidade. II. Título.

$\mathrm{CDD}-339.2$ 


\section{RESUMO}

Esta dissertação busca avaliar o comportamento da renda mediana e da desigualdade de rendimentos tratando o problema de seleção, através de uma abordagem ainda não utilizada em estudos semelhantes no Brasil. A metodologia empregada busca tratar o problema de seleção utilizando apenas hipóteses fracas e pautadas em argumentos econômicos, estimando os menores intervalos possíveis para a distribuição de renda da população. Os resultados obtidos mostram que as medianas dos rendimentos potenciais em 2002 e 2004 eram inferiores aos de 1996. Adicionalmente, a desigualdade de renda potencial recuou no Brasil entre $1996 \mathrm{e}$ 2006. 


\begin{abstract}
This dissertation aims to evaluate the median income and income inequality behavior treating the selection problem with an approach not yet used in similar studies in Brazil. The present methodology tries to address the selection problem using only weak assumptions based on economic arguments, estimating the smallest possible intervals for the population income distribution. The results show that the mean potential income of 2002 and 2004 was smaller than the one of 1996. Additionally, the potential income inequality in Brazil fell from 1996 to 2006.
\end{abstract}




\section{SUMÁRIO}

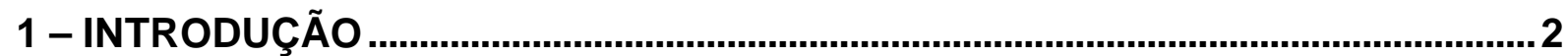

2 - REVISÃO DE LITERATURA

3 - METODOLOGIA

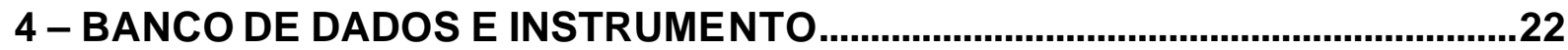

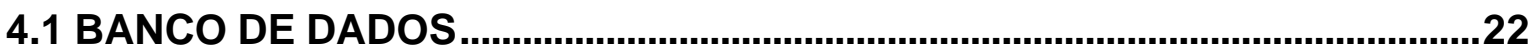

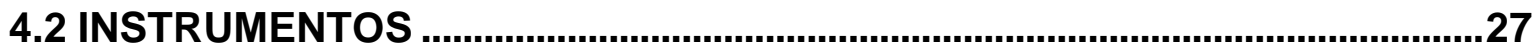

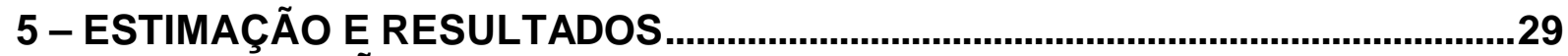

5.1 - ESTIMAÇÃO

5.2- RESULTADOS..................................................................................................31

5.2.1 - MEDIANA DOS RENDIMENTOS.................................................

5.2.1.1 - MEDIANA DOS RENDIMENTOS SOB A RESTRIÇÃO DA

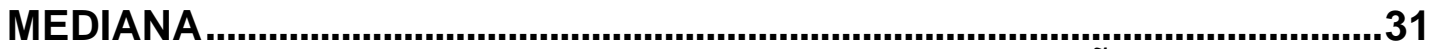

5.2.1.2 - MEDIANA DOS RENDIMENTOS SOB RESTRIÇÃO DA

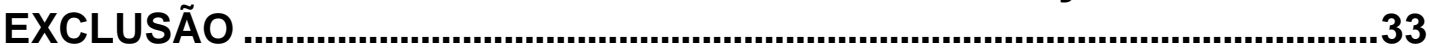

5.2.1.3 - MEDIANA SOB RESTRIÇÃO DA MONOTONICIDADE .................34

5.2.2 - DESIGUALDADE DOS RENDIMENTOS SOB RESTRIÇÃO DA

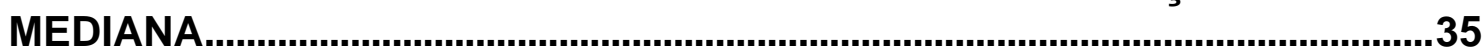

5.2.2.1 - DESIGUALDADE DOS RENDIMENTOS SOB RESTRIÇÃO DA MEDIANA ..........................................................................................

5.2.2.2 - DESIGUALDADE SOB RESTRIÇÃO DA DOMINÂNCIA

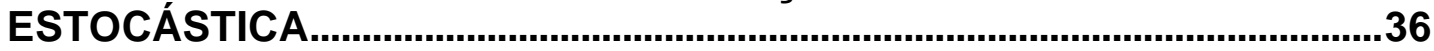

6 - CONCLUSÃO 


\section{1 - INTRODUÇÃO}

Esta dissertação tem por objetivo analisar o comportamento da desigualdade de renda masculina no Brasil no período de 1996 a 2006 considerando todos os homens em idade ativa e não apenas os empregados. Desta forma, busca-se uma medida mais representativa para a desigualdade de renda da população masculina como um todo e não apenas dos homens que estavam trabalhando.

A incorporação dos desempregados à análise busca corrigir um problema observado quando são utilizadas apenas medidas de desigualdade da população empregada. Este problema é conhecido na literatura econômica como "viés de seleção", que consiste na análise de um grupo de pessoas - no caso, os empregados - que não representam a população de interesse como um todo - visto que esta também inclui os desempregados ${ }^{1}$. Este é um problema similar ao de investigar a renda média de uma cidade pesquisando apenas a região mais rica e não através de uma amostra representativa da população.

Todavia, como os desempregados não possuem renda proveniente do trabalho, este trabalho analisará uma medida de renda potencial, que pode ser entendida como a renda que o indivíduo possuiria caso estivesse empregado. De acordo com esta definição, a renda potencial de um desempregado é o salário que ele teria caso estivesse disposto a trabalhar por qualquer remuneração, mesmo que esta remuneração esteja abaixo de um mínimo que considere aceitável. Para os trabalhadores empregados, a renda potencial é o próprio salário.

Desta forma, temos que um desempregado com elevado grau de instrução pode ter uma renda potencial superior aos salários de parcela significativa da população. Este é o caso de executivos que decidem parar de trabalhar por determinados períodos por já terem acumulado uma quantidade de capital significativa ou de alunos que adiam a entrada no mercado de trabalho para estudar por mais tempo e buscar um maior grau de especialização.

O principal objetivo ao se incorporar os desempregados na análise é aprimorar os indicadores de desigualdade de renda como medidas de bem estar de uma sociedade, visto que a distribuição de renda da população masculina em idade ativa pode ser diferente da distribuição da população masculina empregada.

Este seria o caso, por exemplo, em um país marcado por grandes desigualdades sociais, onde as pessoas empregadas possuem salários elevados e razoavelmente homogêneos,

\footnotetext{
${ }^{1}$ Neste trabalho, serão considerados como desempregados todos os homens que não estavam empregados em cada ano, incluindo os que por quaisquer motivos se encontravam fora da força de trabalho.
} 
enquanto os desempregados vivem em situação de miséria. Nessa situação, muito embora sejam verificadas elevadas disparidades sociais, a métrica usual de desigualdade de renda apontaria um quadro de relativa igualdade.

Além disso, a incorporação à análise de movimentos de entrada e saída de trabalhadores na população empregada pode resultar em uma distorção do real comportamento da desigualdade de renda da sociedade. Por exemplo, caso em um determinado ano de crise econômica ocorra um grande número de demissões que afetem principalmente os que ganham menos, o quadro de desigualdade social se agravaria. Ainda assim, o que se verificaria entre o contingente empregado seria uma homogeneização da força de trabalho, que resultaria numa queda da desigualdade de renda medida de acordo com os métodos tradicionais.

Por fim, a incorporação dos desempregados nos permite utilizar a renda potencial, que é uma variável mais indicada para a mensuração de bem estar. Partindo da hipótese de que pessoas com maior renda apresentam, em média, um nível de bem estar mais elevado, a renda potencial informa que um desempregado possui um bem estar superior ao que teria caso estivesse trabalhando e recebendo o salário potencial. Ou seja, uma pessoa que recusou trabalhar por \$100,00 não está pior do que ela estaria caso estivesse trabalhando por este salário, visto que ela considerou ser melhor não trabalhar.

No caso brasileiro, a literatura recente aponta um movimento de contínuas quedas da desigualdade de renda a partir de meados da década de 1990, sendo que a partir de 2001 este movimento teria se tornado mais acentuado. Ademais, aponta-se também que a distribuição de renda de 2005 era certamente menos desigual que a apresentada em 2001 sob quaisquer medidas de desigualdade.

Por conta das limitações apontadas para a desigualdade de renda dos trabalhadores empregados como uma medida de bem estar social, esta dissertação tem por objetivo estudar a desigualdade de renda considerando a existência do viés de seleção. Para tanto, será utilizada uma metodologia não paramétrica utilizada por Blundell et al. (2007; p. 323-363) que busca construir intervalos que contenham a verdadeira distribuição de renda da população, utilizando apenas hipóteses baseadas na teoria econômica.

Todavia, devido ao elevado número de mulheres em idade ativa que não são empregadas e a sensibilidade da metodologia utilizada ao percentual empregado, este estudo não será capaz de incorporar as mulheres na análise. Ademais, esta dissertação não tem por objetivo encontrar os determinantes ou mesmo fornecer opções de políticas de combate a desigualdade de renda. 
Na próxima seção será apresentada uma revisão sobre a literatura de desigualdade de renda, focada em estudos que analisam a queda recente da desigualdade. Na terceira seção será apresentada a metodologia de intervalos ("bounds") empregada neste estudo. Posteriormente são apresentados os dados. Na quinta seção são apresentados os resultados e na sexta seção as conclusões. 


\section{2 - REVISÃO DE LITERATURA}

A desigualdade de renda no Brasil é um tema bastante explorado por economistas desde meados no século XX, o que possibilita observar as mudanças da distribuição de renda ao longo das últimas cinco décadas. Langoni (1973), Bonelli e Ramos (1995; pp. 353-73) e Hoffmann (2001), utilizando microdados da PNAD e do Censo, mostram que a desigualdade de renda medida pelo índice de Gini piorou entre 1960 e 1990 e depois apresentou uma melhora até 1999, retornando a um patamar próximo ao verificado em 1970. Já a desigualdade da renda familiar per capita, mensurada a partir de 1977, não apresentou o mesmo comportamento, tendo permanecido relativamente estável durante todo o período.

Menezes-Filho (2001; p. 13-50) apresenta uma análise qualitativa dos fatores que impactaram a queda da desigualdade. De acordo com o autor, houve mudanças de características populacionais, tais como aumento de desigualdades educacionais e redução da oferta de trabalhadores com nível superior, que retardaram a queda dos diferenciais salariais observados nas décadas de 1980 e 1990. Do lado da demanda relativa por trabalhadores, o autor aponta um aumento da procura por profissionais com níveis médio e superior, sendo ainda necessário investigar os impactos da redução da qualidade do ensino público no Brasil.

Sobre a queda da desigualdade de renda no Brasil a partir de 2001, foi publicada uma quantidade significativa de estudos que investigaram diversos aspectos relevantes, entre os quais merecem destaque: (i) adoção de diferentes medidas de desigualdade, (ii) critérios mais rigorosos para confirmar a significância estatística dos resultados, (iii) controle de fluxos de capital não mensurados pela PNAD, (iv) utilização de outras medidas de renda, como o rendimento médio domiciliar, (v) diferenças na composição familiar entre classes econômicas distintas e (vi) adoção de índices de inflação específicos para a cesta de bens consumida por cada classe social.

IPEA (2006) aponta que o total dos rendimentos dos $1 \%$ mais ricos do país é similar ao verificado pelo total da metade mais pobre da população, o que faz com que $95 \%$ dos paises com dados disponíveis apresentem distribuições de renda mais justas que a brasileira. Apesar disso, a nota técnica aponta que o descompasso de rendimentos se encontra em trajetória declinante desde a segunda metade da década de 1990 e que o movimento de queda teria se intensificado a partir de 2001. 
Hoffmann (2007) investiga o comportamento da desigualdade de renda da população economicamente ativa e dos rendimentos domiciliares per capita no período de 1995 a 2005 através dos índices de Gini, do $\mathrm{T}$ de Theil e dos valores observados para determinados percentis de renda. Os dados utilizados foram os dados da PNAD. O autor conclui que a partir de 1995 a desigualdade de renda no país inicia uma trajetória declinante, que se acentua em 2001. Ademais, a comparação da distribuição da renda domiciliar per capita aponta que em 2005 a proporção de pobres diminui.

Barros et al. (2007b), por sua vez, investigaram o comportamento da desigualdade de renda através do índice de Gini e da curva de Lorenz utilizando dados da PNAD de 1995 a 2005. Além disso, o autor utiliza evidências históricas e internacionais para avaliar a significância das transformações verificadas nesse período. Os resultados encontrados apontam que a desigualdade de renda no Brasil recuou de forma contínua e acentuada a partir de 2001 e atingiu em 2005 o patamar mais baixo desde meados da década de 1970 de acordo com a maioria dos índices de desigualdade. Ainda assim, o Brasil continuou a ser um dos países mais desiguais do mundo em termos de renda.

Soares (2006; 83-115) analisa o comportamento da desigualdade de renda medida pelo índice de Gini, T de Theil, razão 10/40 e razão 20/20. Seus resultados mostram que a trajetória de queda da desigualdade iniciou em 1995 e acelerou em 2001, explicada principalmente pelos rendimentos do trabalho, que explicam $73 \%$ da variação do índice de Gini. Além disso, o autor argumenta que a distribuição de renda de 2004 domina no sentido de Lorenz todos os anos desde 1976, a exceção de 1981 e 1984.

Já Neri (2007) busca quantificar o movimento de queda da desigualdade de renda a partir de 2001 e analisar seus impactos mais relevantes, utilizando para isso medidas tradicionais de desigualdade e outras menos utilizadas, como uma função de bem estar social. Os dados utilizados foram os da PNAD. Os resultados apontam que a queda da desigualdade de renda iniciada em 2001, após três décadas de relativa estagnação, atenuou os efeitos do período recessivo do biênio 2002-2003 sobre o crescimento da miséria. Ademais, o autor argumenta que a manutenção da trajetória recente de queda da desigualdade associada a um crescimento anual de $4,5 \%$ por quatro anos consecutivos levaria a uma redução da miséria em $34,05 \%$, muito embora isso não implique que o Brasil deixaria de ser um dos paises mais desiguais do planeta.

Em outra linha de abordagem, Osório e Soares (2007) argumentam que o estudo da desigualdade renda serve como uma medida para o bem estar e por isso não pode ser deflacionado a partir de uma única medida de inflação, pois desse modo não se controlaria 
mudanças de preços relativos. Os autores defendem esse ponto utilizando evidências encontradas para outros paises, tais como Coréia do Sul e Tailândia, onde variações de preços afetaram de forma mais significativa os mais pobres. Para elaborar o estudo os autores utilizam dados da PNAD, da Pesquisa de Orçamentos Familiares (POF) e o Índice de Preços ao Consumidor Amplo (IPCA).

Os resultados encontrados para o Brasil apontam que as mudanças de preços relativos ocorridas entre 1994 e 2005 foram benéficas aos mais pobres. Com isso, obtêm-se uma evidência que os estudos sobre desigualdade de renda que utilizam um índice homogêneo para deflacionar a amostra podem estar subestimando o verdadeiro declínio da desigualdade no Brasil.

Agostinho et al. (2007), por sua vez, argumentam que é preciso avaliar a desigualdade da renda familiar per capita para se levar em consideração as diferentes composições entre crianças e adultos existentes em famílias de classes sócio-econômicas distintas. No entanto, os autores não encontraram nenhum impacto significativo de mudanças demográficas sobre a queda da desigualdade de renda verificada a partir de 2001.

Outros dois estudos foram elaborados para checar a validade das medidas de desigualdade de renda. Azevedo (2007) aponta que os métodos de estimação dos desvios padrão das medidas de desigualdade muitas vezes geram estimativas ruins das variâncias, necessárias para comparar a desigualdade entre dois períodos, por conta da complexidade das funções utilizadas para a estimação das medidas de desigualdade. Em função dis so, o autor utilizou um método de estimação para funções complexas e estimou valores para as variâncias do Índice de Gini e da Curva de Lorenz. Os novos resultados confirmam os resultados anteriores de queda da desigualdade de renda entre 2001 e 2005.

Já Barros et al. (2007c) investigam se a subestimação dos rendimentos familiares decorrentes da incapacidade da PNAD em captar algumas formas de rendimentos, tais como seguro desemprego e rendimentos de ativos, impacta na aferição da desigualdade de renda a partir desse banco de dados. Para tanto, os autores confrontaram os dados da PNAD com os da POF e as Contas Nacionais para cobrir parte dessa lacuna e aferir o potencial impacto dessa subestimação.

Os resultados encontrados apontam para uma subestimação da renda medida pela PNAD da ordem de $26 \%$ a $27 \%$ quando comparada tanto com as Contas Nacionais como com a POF. Os autores argumentam que o fator mais importante dessa diferença são as transferências de rendas, enquanto que os rendimentos de ativos são o terceiro fator. Por conta disso, é possível que a desigualdade esteja subestimada ou sobreestimada dependendo da 
medida utilizada. Simulações elaboradas para o período de 2001 a 2005 apontam para uma subestimação da desigualdade nos primeiros três anos, o que indica que não houve uma superestimação da recente queda da desigualdade de renda.

Além desses estudos já citados, Barros et al. (2007a) buscam quantificar as contribuições dos determinantes da queda da desigualdade de renda via simulações contrafactuais, encontrando que os rendimentos não derivados do trabalho e a renda derivada do trabalho por trabalhador explicavam entre $46 \%$ e $48 \%$ da queda da desigualdade de renda entre 2001 e 2005.

A principal conclusão obtida através da análise dos estudos apresentados é que a desigualdade de renda apresentou uma clara e acentuada trajetória de queda entre 2001 e 2005, de modo que, sob qualquer medida de desigualdade utilizada, a distribuição de 2005 era menos desigual que a de 2001 - denominado de dominância de Lorenz. Todavia, todos os trabalhos reportam a desigualdade de renda da população empregada, o que não equivale à desigualdade da população como um todo. Dessa forma, esta dissertação tem por objetivo ampliar o debate sobre a desigualdade de renda examinando toda a população masculina em idade ativa utilizando uma metodologia de construção de intervalos (“bounds”). 


\section{3 - METODOLOGIA}

A metodologia empregada nesta dissertação tem por objetivo medir a desigualdade da renda potencial da população economicamente ativa para o período de 1996 a 2006 . Dessa forma, busca-se encontrar uma medida para a desigualdade de renda que seja mais representativa da população como um todo e não apenas das pessoas que trabalhavam e tinham seus rendimentos auferidos.

Neste trabalho, assumimos que cada indivíduo possui uma força de trabalho que pode ser vendida no mercado, ou seja, que pode trabalhar para outras pessoas e em troca receber um salário. O fato de uma pessoa estar desempregada não significa que ela não possui uma força de trabalho, mas sim que ela não encontrou quem pagasse pelo seu trabalho o mínimo que ela esperava receber (o salário de reserva).

Desse modo, o rendimento potencial é definido como a oferta salarial que um indivíduo recebeu em troca de sua força de trabalho, independentemente de ter aceitado ou não. Dessa forma, a renda potencial de um trabalhador empregado é igual ao salário recebido e pode ser observado. Já a renda potencial dos desempregados não pode ser observada, por ser menor que seu salário de reserva.

Como o salário potencial dos desempregados não pode ser observado, não é possível fazer qualquer afirmação sobre sua magnitude, sendo que ele pode ser igual a zero, o que implica que ninguém estaria disposto a pagar qualquer quantia para contratar este desempregado, ou então superior ao de qualquer funcionário empregado, implicando que o indivíduo prefere não trabalhar mesmo sendo muito bem valorado no mercado. Muito embora o bom senso indique que os salários potenciais médios se encontrem entre esses dois extremos, não é possível afirmar muito sobre eles sem a imposição de hipóteses a priori.

Para melhor compreender o problema do salário potencial, utilizaremos um exemplo apresentado em Manski (2007). Seja Y uma variável condicionada em X, de tal modo que $\mathrm{P}(\mathrm{Y} / \mathrm{X})$ é a distribuição de $\mathrm{Y}$ dado $\mathrm{X}$. Adicionalmente, $\mathrm{X}$ pode assumir apenas os valores inteiros 1 e 2 , sendo $Y$ observado apenas quando $X=2$. No caso do presente estudo, $Y$ pode ser a renda potencial e X a condição da pessoa entre empregado e desempregado.

Com um número suficiente de observações de Y e X, é possível estimar a distribuição de $Y$ quando $X=2$, mas não é possível quando $X=1$ (ilustração 1). Desse modo, temos que a distribuição de Y não é passível de ser estimada unicamente a partir das observações 
disponíveis sem que seja necessário impor alguma restrição sobre a distribuição de Y quando $\mathrm{X}=1$.

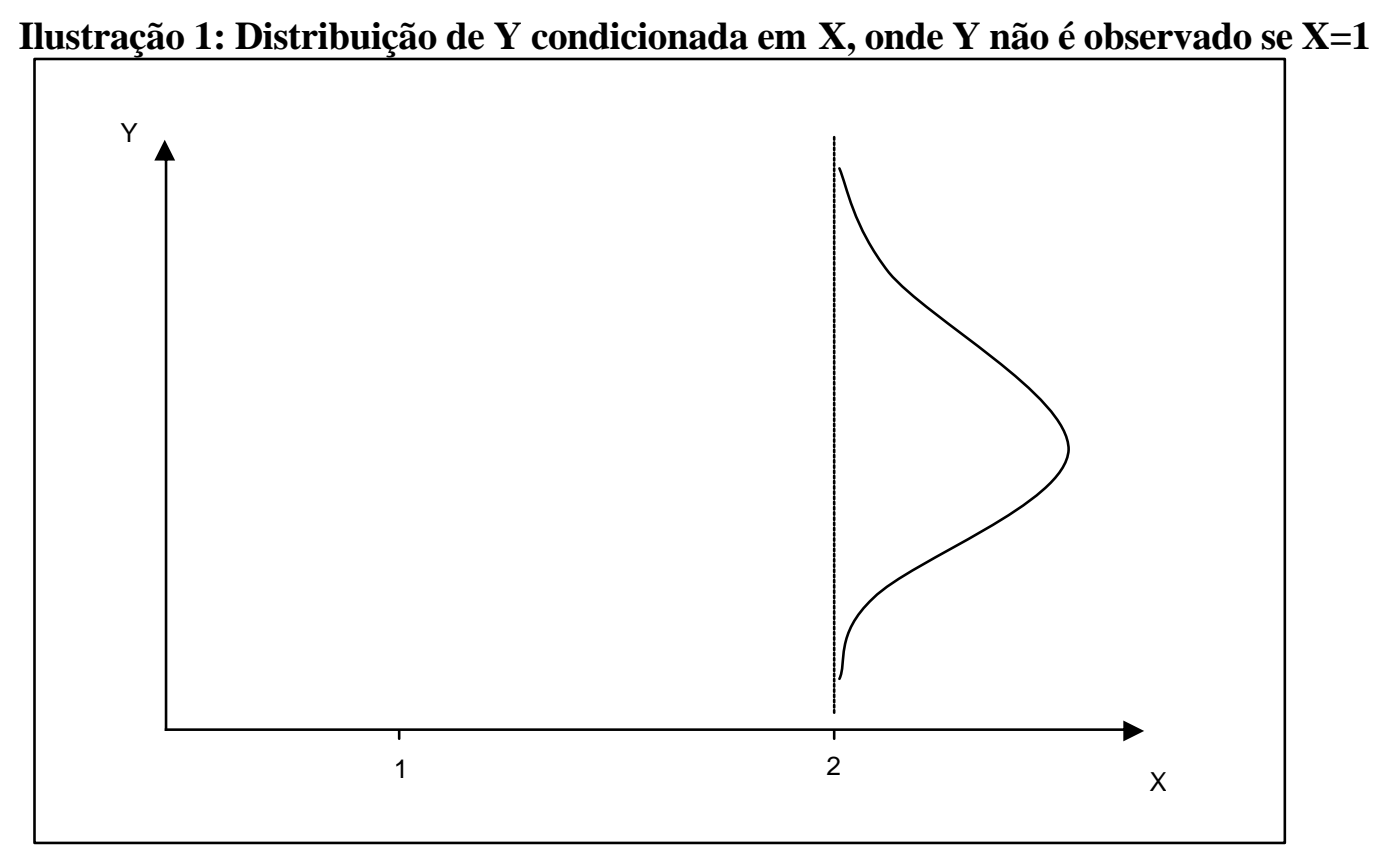

A primeira implicação da existência de salários potenciais é que o estudo da desigualdade de renda potencial não pode ser elaborado supondo que todos os desempregados possuem renda igual a zero. Devido à existência de desempregados com salários potenciais superiores a zero, esse tipo de abordagem gera resultados inconsistentes, que não refletem o estado real da economia.

A segunda implicação da existência de salários potenciais é que a desigualdade de renda dos trabalhadores só pode ser assumida como sendo igual à da sociedade sob a hipótese que a renda potencial dos trabalhadores tem a mesma distribuição da renda potencial dos desempregados. Neste caso, a igualdade das distribuições seria o equivalente a supor que não existe o problema de seleção, ou seja, a amostra coletada é representativa da população.

O problema desta hipótese é que ela relega ao segundo plano a possibilidade dos desempregados apresentarem características distintas que não sejam observáveis pelo pesquisador e que sejam importantes para a definição da renda. Por exemplo, é provável que, em média, as pessoas empregadas possuam um grau de disciplina e perseverança distinto da média dos desempregados. E se isto se verificar, as distribuições de renda dos desempregados não são iguais à distribuição de renda dos empregados.

Em função destas limitações, existe uma vasta literatura sobre abordagens do viés de seleção. A literatura começa com Tobin (1956; p. 24-36) e ganha um maior destaque com 
Heckman (1979; p. 153-161), cujas metodologias utilizam variáveis latentes e hipóteses paramétricas para estimar o impacto da parte não observada. A partir destes trabalhos a metodologia sobre viés de seleção se desenvolveu, com a criação de novas abordagens, tal como o método Propensity Score Matching (ver Rosembaum (1983; p. 41-55)), e com o aprimoramento dos métodos tradicionais (ver Ahn e Powell (1993; p. 3-29) sobre estimação do modelo de Heckman sob hipóteses mais fracas).

Cabe ressaltar que essas metodologias não surgem para promover novas formas de estimar a distribuição da variável quando ela é observada. Elas buscam fornecer diferentes hipóteses e teorias sobre como extrapolar os resultados obtidos na parcela observada da população para derivar a distribuição da parcela não observada.

Esta dissertação busca utilizar outra abordagem para o problema de viés de seleção, utilizando a metodologia de intervalos (“bounds") desenvolvida por Manski (1994) e apresentada em Blundell et al. (2007; p. 323-363). A idéia por trás deste método é construir duas distribuições de renda que representem os casos limites que poderiam acontecer: ou os desempregados apresentam salários potenciais iguais à zero ou bastante elevados.

Neste caso não se estabelece qual a distribuição populacional, mas sim o menor intervalo que contenha a verdadeira distribuição sem que seja necessário impor alguma restrição sobre a distribuição do salário potencial dos desempregados. Uma vez estabelecido o menor intervalo que contenha a distribuição verdadeira da renda potencial, são utilizadas hipóteses intuitivas e pautadas na teoria econômica para diminuir a amplitude do intervalo.

Depois de encontrados os limites superiores e inferiores das possíveis distribuições de renda, utiliza-se o inverso das funções das distribuições para encontrar os respectivos salários das distribuições extremas e, desta forma, constrói-se o intervalo para a distribuição dos rendimentos potenciais.

Seja W a variável endógena (no caso o salário potencial) e $\mathrm{Z}$ uma variável binária que assume valores 0 quando $\mathrm{W}$ é não observado e 1 quando $\mathrm{W}$ é observado - ou seja, quando a pessoa está empregada. Como esta metodologia pode ser empregada para medir a desigualdade da população como um todo ou de subgrupos populacionais, define-se X como o conjunto de variáveis exógenas, tais como idade e gênero, que podem ser utilizadas para a construção dos grupos de interesse. Por fim, defina-se $\mathrm{P}(\mathrm{x})$ como a probabilidade de $\mathrm{z}=1$ dado $\mathrm{X}=\mathrm{x}$. Então, temos que:

$$
F(W / x)=F(W / x, z=0)[1-P(x)]+F(W / x, z=1) P(x)
$$


onde $F(W / x)$ é a função probabilidade acumulada dos salários potenciais para o grupo de interesse, que apresentam as características observáveis $\mathrm{x}$, sendo que este grupo pode ser constituído por toda a população. A distribuição acumulada da renda do trabalho é a soma das distribuições dos salários das pessoas que trabalham ponderada pela probabilidade da pessoa estar empregada (as quais são observáveis e, portanto, estimáveis) com a distribuição não observável daqueles que não trabalham, $F(W / x, z=0)$.

Como por definição $F(W / x, z=0)$ só pode assumir valores entre zero e um, $F(W / x, z=1)$ é observável e $\mathrm{P}(\mathrm{x})$ é um valor estimável, temos que é possível determinar um intervalo para $F(W / x)$ substituindo $F(W / x, z=0)$ por 0 e 1 . Esta transformação implica que para qualquer salário de reserva $\mathrm{W}$, os casos extremos são: (i) todos os desempregados poderiam ganhar mais que $\mathrm{W}$, neste caso $F(W / x, z=0)=0$, ou (ii) todos os desempregados possuem salário potencial inferior a $\mathrm{W}$, o que implica $F(W / x, z=0)=1$. Portanto, o limite superior da distribuição populacional $F(W / x)$ na equação (2) é o caso em que todos os desempregados possuem salários potenciais menores que $\mathrm{W}$, enquanto o limite inferior considera a situação que esses salários potenciais são maiores.

$$
F(W / x, z=1) * P(x) \leq F(W / x) \leq F(W / x, z=1) * P(x)+[1-P(x)]
$$

Já para encontrar intervalos da distribuição acumulada para determinados valores de $F(w / x)$ (útil para estimar a razão entre o primeiro e quarto quartil, por exemplo), é possível reescrever a função (2). Neste caso, como $F(W / x)$ seria determinado previamente e $\mathrm{P}(\mathrm{x})$ pode ser estimado, só falta encontrar os valores da distribuição acumulada dos empregados $F(W / x, z=1)$ que atendem a desigualdade (2). Rearranjando a equação (2) para encontrar $F(W / x, z=1)$ temos:

$$
\begin{aligned}
& F(W / x, z=1) \leq \frac{F(W / x)}{P(x)} \\
& F(W / x, z=1) \geq 1-\frac{1-F(W / x)}{P(x)}
\end{aligned}
$$


A equação (3) informa o limite inferior da distribuição acumulada da distribuição dos salários dos trabalhadores empregados que satisfaz a restrição (2) enquanto a equação (4) fornece o limite superior. Partindo destas duas relações, é possível encontrar o intervalo para os salários correspondentes aos limites encontrados para $F(W / x, z=1)$, que é dada pelas inversas das desigualdades (3) e (4).

Como o limite superior da distribuição considera que todos os desempregados têm renda inferior a $\mathrm{W}$, o maior salário potencial encontrado através da inversa do limite superior da distribuição acumulada (5) é igual ao limite inferior do salário potencial, ou seja, o menor valor que o salário potencial pode assumir. De igual forma, a inversa da desigualdade do limite inferior da distribuição (6) fornece o limite superior da renda potencial:

$$
\begin{aligned}
& W \leq F^{-1}\left(\begin{array}{c}
F(W / x) / P(x) \\
\mathrm{e}
\end{array}\right. \\
& W \geq F^{-1}(1-F(w / x) / P(x))
\end{aligned}
$$

Para melhor compreender a metodologia, tomemos o seguinte exemplo. Suponha que para um dado conjunto de características $X=\bar{X}$ deseja-se encontrar qual o intervalo para $F(W / x)=25 \%$ sabendo-se que a probabilidade de se estar empregado é de $90 \%$. Neste caso, teríamos que o intervalo dos salários seria aquele que respeitasse a desigualdade $\frac{0,25}{0,9} \geq F(W / x, z=1) \geq 1-\frac{1-0,25}{0,9}$, sendo os valores limites obtidos com a igualdade em cada um dos extremos. Ou seja, os possíveis salários potenciais recebidos pelo primeiro quartil da população são não menores que os obtidos por $16,7 \%$ dos empregados e não maiores que de $27.8 \%$ dos empregados.

Outro modo de entender este procedimento é ordenar todos os trabalhadores de acordo com seus salários e depois construir os dois cenários mais extremos possíveis: um em que todos os desempregados possuem salários potenciais muito baixos e outro onde eles possuem salários potenciais muito elevados. Para isto, suponha uma economia com oito pessoas desempregadas e cem empregadas, onde o grupo de interesse é constituído por toda a população. Suponha também que os trabalhadores estejam ordenados de acordo com seus salários, onde o primeiro recebe $\$ 1,00$, o segundo $\$ 2,00$ até o centésimo com rendimentos de 
\$100,00. Assim, teríamos que o salário verificado no primeiro quartil dos empregados $(F(W / x, z=1)=25 \%)$ seria igual a $\$ 25,00$.

Para calcular o intervalo para $F(W / x)=25 \%$ considerando a população como um todo, suponha inicialmente que todos os desempregados possuem salários potencias inferiores a \$ 1,00. Isto implica que a população de interesse é composta agora por 108 indivíduos e que cada quartil contém 27 pessoas. Portanto o salário potencial do $27^{\circ}$ indivíduo, lembrando que os oito desempregados aparecem agora no começo da ordenação, corresponde ao salário do $19^{\circ}$ dos que realmente trabalham, ou seja, é igual a \$19,00. Realizando operação análoga, encontramos um limite superior de \$27,00 - ver ilustração abaixo.

\section{Ilustração 2 - Casos extremos dos salários potenciais - elevados e baixos, respectivamente}

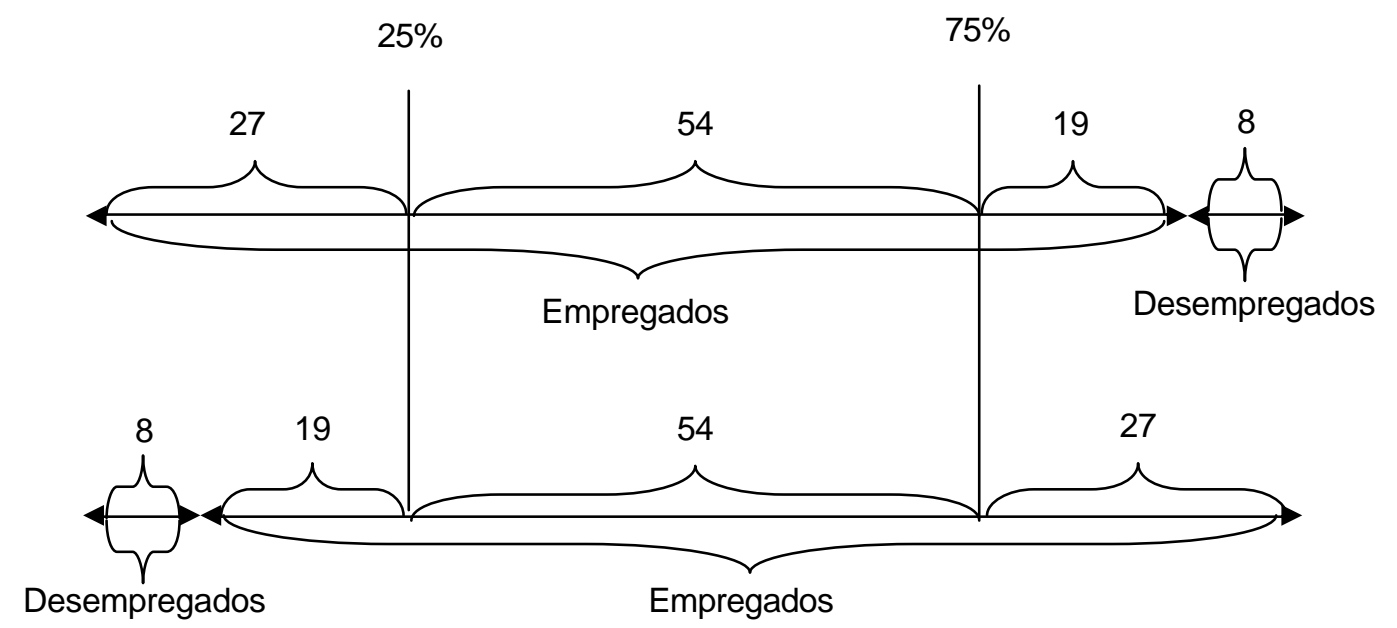

Ao operar esta passagem, chega-se ao menor intervalo que pode ser estimado sem a utilização de nenhuma restrição sobre a probabilidade de estar empregado ou da distribuição de W em z para qualquer grupo x. Estes intervalos podem ser úteis para o cálculo da mediana de rendimentos ou mesmo de algumas medidas de desigualdade de renda, tais como a razão entre alguns percentiis de renda.

Todavia, estes intervalos podem não ser estreitos o suficiente para se chegar a alguma conclusão dependendo da probabilidade de se estar empregado, ou para o cômputo de outras medidas de desigualdade, tal como o Índice de Gini. No exemplo anterior não é possível determinar os limites dos intervalos para probabilidades acumuladas maiores que 
$F(W / x) \geq 100 / 108 \approx 92,6 \%$. Já para todos os valores da distribuição acumulada menores que $F(W / x) \leq 8 / 108 \approx 7,4 \%$ o limite inferior do rendimento potencial seria zero.

Ainda de acordo com o exemplo anterior, para calcular a desigualdade de rendimentos entre o primeiro e o quarto quartil seria primeiro necessário estimar o intervalo para o último quartil, que seria de $\$ 73,00$ a $\$ 81,00$. Depois, pode-se estimar a pior desigualdade possível dividindo o maior salário possível para o primeiro quartil pelo menor possível no quarto quartil, obtendo-se um coeficiente $d^{I}=81 / 19 \cong 4.26$. De maneira análoga, o menor coeficiente neste caso seria $d^{S}=73 / 27 \cong 2.70$.

Todavia, não seria possível estimar medidas de desigualdade que necessitem de intervalos para probabilidades acumuladas muito pequenas ou elevadas, tais como $F(W / x)=1 \%$ ou $F(W / x)=99 \%$, o que impossibilita estimar medidas como o Índice de Gini ou a curva de Lorenz.

Para restringir o tamanho dos intervalos serão utilizadas quatro restrições, sendo que a validade das duas últimas será testada. A primeira é uma hipótese sobre a mediana da distribuição dos salários potenciais dos desempregados. Posteriormente, será suposto que a distribuição de renda dos assalariados domina estocasticamente a renda potencial. A terceira restrição é uma hipótese de exclusão utilizando um instrumento que seja independente da variável dependente condicionada nos anos de estudo. Por fim, será relaxada a hipótese de independência entre a variável dependente e o instrumento, impondo-se uma restrição de monotonicidade.

\section{1 - Restrição sobre a mediana}

A primeira restrição será assumir que a mediana dos salários oferecidos aos indivíduos desempregados da população de interesse é inferior à mediana observada entre os trabalhadores. Em outras palavras, isso significa que todos os desempregados podem ter salários potenciais menores que a mediana dos salários dos assalariados, mas apenas metade dos desempregados pode possuir salários potenciais superiores a mediana dos salários dos assalariados.

Com isto, impõe-se que existe um viés de seleção positivo no mercado de trabalho, dado que na melhor das hipóteses o salário potencial mediano entre os desempregados é igual à mediana dos assalariados. Isto implica que 


$$
\begin{array}{lr}
0 \leq F(W / x, z=0) \leq 1 & \text { se } W(x) \leq W^{50(z=1)}(x) \\
0.5 \leq F(W / x, z=0) \leq 1 & \text { se } W(x) \geq W^{50(z=1)}(x)
\end{array}
$$

Utilizando esta restrição é possível redefinir o intervalo da distribuição de W condicional a $\mathrm{X}$ e $\mathrm{Z}$ de tal modo que

$$
\begin{aligned}
& F(W / x, z=1) * P(z=1 / x) \\
& \leq F(W / x) \leq \\
& F(W / x, z=1) * P(z=1 / x)+[1-P(z=1 / x)] \\
& \text { se } W(x) \leq W^{50(z=1)}(x) \\
& F(W / x, z=1) * P(z=1 / x)+0.5 *[1-P(z=1 / x)] \\
& \leq F(w / x) \leq \\
& F(W / x, z=1) * P(z=1 / x)+[1-P(z=1 / x)] \\
& \text { se } W(x) \geq W^{50(z=1)}(x)
\end{aligned}
$$

Utilizando a estrutura definida anteriormente, podemos rearranjar esta equação para encontrar o intervalo de $F(w / x, z=1)$ para um determinado valor de $F(w / x)$, de tal forma que:

$$
\begin{aligned}
& F(W / x, z=1) \leq \frac{F(W / x, z=1)+(P(z=1 / x)-1)}{P(z=1 / x)} \\
& F(W / x, z=1) \geq \frac{F(W / x, z=1)+0.5(P(z=1 / x)-1)}{P(z=1 / x)}
\end{aligned}
$$

Seguindo o primeiro exemplo, onde se buscava encontrar o intervalo para $F(W / x)=25 \%$ dada a probabilidade de estar empregado $P(z=1 / x)=90 \%$, a restrição da mediana não seria ativa, pois nada impede que todos os desempregados possuam salários potenciais superiores àquele correspondente ao de $F(W / x, z=1)=25 \%$. Todavia, para $F(W / x)=75 \%$ a restrição passa a ser ativa, fazendo com que o intervalo se reduzisse de $72.2 \% \leq F(W / x, z=1) \leq 83.3 \%$ para $72.2 \% \leq F(W / x, z=1) \leq 77.8 \%$.

Já no segundo exemplo, a renda mediana dos assalariados era igual a $\$ 50,00$ e existiam 8 desempregados. Sob a restrição da mediana, teríamos que apenas 4 desempregados poderiam ter salários potenciais superiores a $\$ 50,00$. Com isto, o intervalo para 
$F(W / x)=25 \%$ não se altera, mas para $F(W / x)=75 \%$ verifica-se uma redução do limite superior de \$ 81,00 para \$77,00 (ilustração 3).

\section{Ilustração 3 - Casos extremos dos salários potenciais sob restrição da mediana}

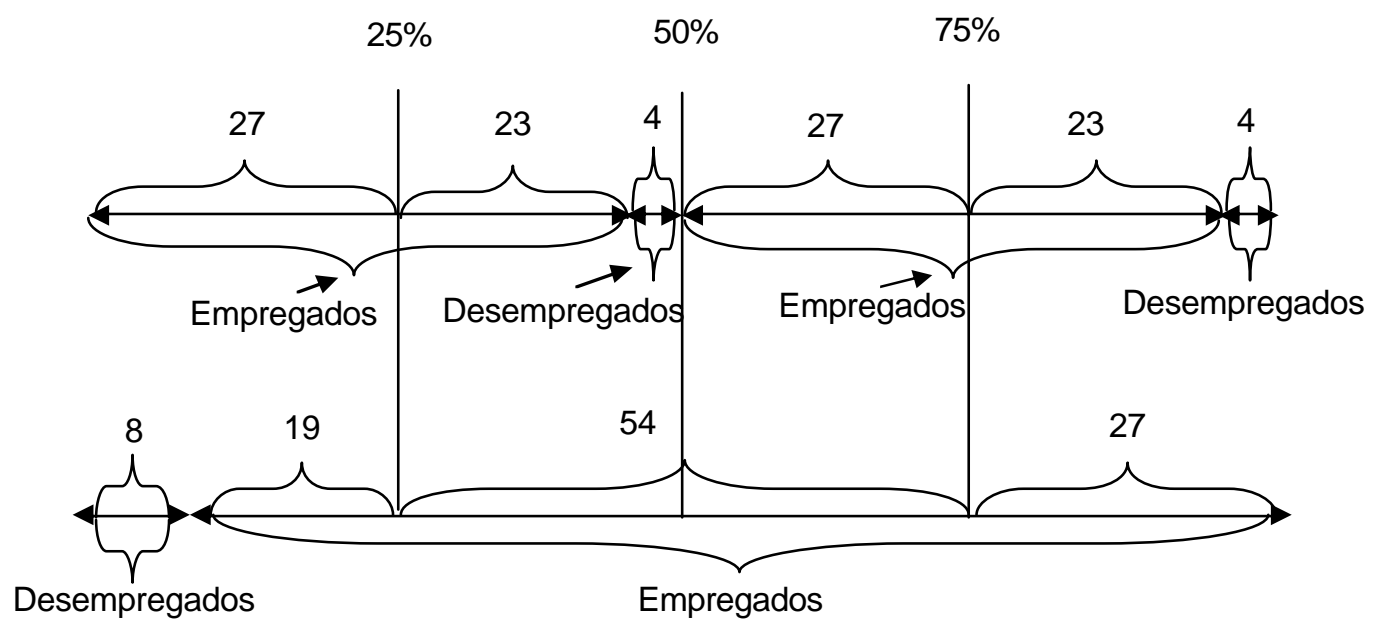

\section{2 - Dominância estocástica}

Seja $F(W / x, z=1)$ a função densidade acumulada dos trabalhadores e $F(W / x, z=0)$ a dos desempregados para um determinado grupo que apresente características $\mathrm{x}$. Temos então que $F(W / x, z=1)$ domina estocasticamente $F(W / x, z=0)$ se, para qualquer salário potencial W:

$$
F(W / x, z=1) \leq F(W / x, z=0)
$$

Ou seja, o percentual de desempregados com salários potenciais iguais ou menores que $\mathrm{W}$ é maior que o percentual de empregados que recebem até W. Isso implica na existência de um forte viés de seleção, limitando que a distribuição de renda dos desempregados não seja melhor que a dos empregados. Com isso, é possível encontrar os limites para os intervalos de quaisquer $F(W / x)$, por mais elevado que seja.

A principal vantagem desta restrição é possibilitar o emprego de uma maior variedade de medidas de desigualdade ao determinar os limites superiores para os intervalos dos salários 
potenciais. Com isso, é possível encontrar duas distribuições extremas da renda potencial que sejam bem definidas, mesmo que o desemprego se encontre relativamente alto.

Voltando ao exemplo anterior, com uma população de 100 pessoas empregadas e 8 desempregadas, para encontrar os limites superiores dos intervalos basta assumir que a distribuição populacional é igual a distribuição dos empregados. Assim, o salário potencial que limita superiormente o intervalo $F(W / x)=25 \%$ é igual ao salário $F(W / x, z=1)=25 \%$, ou seja, \$25,00. Já o limite superior não é afetado, permanecendo em \$19,00. De igual forma, o intervalo para $F(W / x)=75 \%$ está entre $\$ 73,00$ e $\$ 75,00$.

\section{Ilustração 4 - Casos extremos dos salários potenciais sob restrição da mediana}

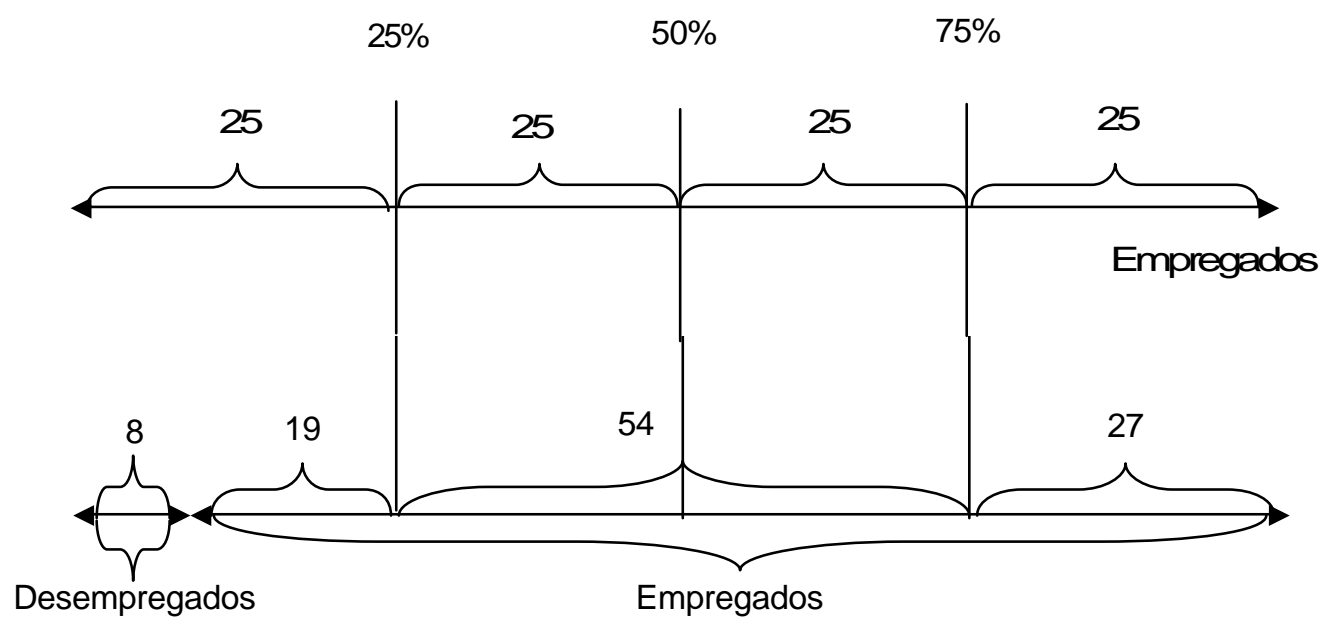

Esta restrição é razoavelmente forte quando considerados alguns grupos socioeconômicos. Por exemplo, mulheres de meia idade casadas com homens ricos podem estar desempregadas mesmo possuindo salários potenciais elevados, bastante acima da remuneração média de mulheres com as mesmas características. Em casos como esse, é de se esperar a não validade desta restrição, embora para a população como um todo ela seja bem mais razoável.

\section{3 - Restrição de exclusão}

Manski (1994) mostra que se uma variável Y é independente de W uma vez controlado por X, ou seja, se 


$$
F(W / X, Y)=F(W / X) \quad \forall W, X e Y
$$

Então a distribuição condicional de $\mathrm{W}$ dado $\mathrm{X}$ pode ser reescrita por

$$
\max _{Y} F(W / z=1, x, y) P(x, y) \leq F(W / x) \leq \min _{Y} F(W / z=1, x, y) P(x, y)+1-P(x, y)
$$

A idéia por trás desta hipótese é que sendo a distribuição dos salários independente do instrumento, uma vez controladas pelas características observáveis dos indivíduos, pode-se constituir novos grupos para cada valor assumido pelo instrumento. A partir dis so, têm-se que o verdadeiro intervalo da distribuição se encontra entre o maior limite inferior observado entre os grupos conjuntamente com o menor limite superior. Com isso, o limite inferior pode ser elevado até o maior valor que ele possa apresentar para um determinado $\mathrm{Y}$ e, de maneira análoga, o limite superior é reduzido.

Por conta disso, é fundamental que a hipótese de independência entre W e Y dado X seja respeitada, pois, caso contrário, pode-se obter um cruzamento entre os limites superior e inferior. Ou seja, caso o uso da restrição de exclusão implique que em algum momento o limite superior dos salários esteja abaixo do limite inferior, isso deve ser atribuído à não validade da hipótese (14).

\section{4 - Restrição de monotonicidade}

Um meio de relaxar a hipótese da restrição de exclusão é trabalhar com uma de monotonicidade, permitindo que a distribuição dos salários dependa do instrumento $\mathrm{Y}$

$$
F\left(W / x, Y^{\prime}\right) \leq F(W / x, Y) \quad \forall W \text {, y e } y^{\prime} \operatorname{com} Y \leq Y^{\prime}
$$

Isto resulta em uma restrição similar a da dominância estocástica, só que determinada pelo instrumento, de modo que os grupos que apresentam um maior (menor) valor do instrumento dominam estocasticamente os grupos com menor (maior) valor do instrumento. Blundell et al. (2007; p. 323-363) mostram que os limites superiores e inferiores podem ser definidos como 


$$
\begin{aligned}
& F\left(W / x, Y_{1}\right) \geq F^{l}\left(W / x, Y_{1}\right) \equiv \max _{Y \geq Y_{1}} F(W / z=1, x, Y) P(x, Y) \\
& F\left(W / x, Y_{1}\right) \leq F^{u}\left(W / x, Y_{1}\right) \equiv \min _{y \leq y_{1}} F(W / z=1, x, Y) P(x, Y)+1-P(x, Y) \\
& E\left[F^{l}(W / x, Y) / x\right] \leq F(W / x) \leq E\left[F^{u}(W / x, Y) / x\right]
\end{aligned}
$$

Esse resultado mostra que o limite inferior do intervalo da distribuição populacional é dado pela esperança da distribuição acumulada no instrumento. O limite superior é obtido de maneira análoga. Uma vez determinados os valores das probabilidades acumuladas dos limites inferior e superior da distribuição da renda potencial, é possível repetir o procedimento usual para encontrar o intervalo dos salários potenciais.

\section{5 - Método de interpretação dos resultados}

Devido às características da metodologia utilizada, que não permite identificar intervalos para todos os pontos da distribuição de renda, não será possível utilizar muitos dos testes usuais. Em função disso, será utilizado como medida da desigualdade a razão entre o primeiro e quarto quartis dos salários, sendo que quanto maior o valor da razão maior é a desigualdade associada.

Uma vez estabelecidos os menores intervalos que englobam as possíveis distribuições de renda nos diferentes anos, será possível analisar o comportamento da desigualdade de renda no Brasil. Para constatar que a desigualdade recuou, será preciso que o limite inferior do intervalo de 1996 seja superior ao limite superior de 2006. Caso o contrário (se verifique que o limite inferior de 2006 seja maior que o limite superior de 1996), terá ocorrido um aumento da desigualdade. Caso nenhuma destas combinações se verifique o resultado não será conclusivo.

Todavia, por ser utilizada uma amostra populacional, faz-se necessário encontrar intervalos de confiança para os limites estimados. Para isso, utiliza-se o bootstrap não paramétrico para a obtenção de intervalos de confiança para os limites dos intervalos das distribuições de renda. Desta forma, para constatar uma variação do quadro de desigualdade de renda será necessário considerar os intervalos de confiança dos limites superior e inferior da renda. 
A estimação dos intervalos de confiança dos limites superiores e inferiores dos intervalos é realizada considerando um intervalo de confiança de $95 \%$. O procedimento utilizado é o seguinte:

- São construídas 200 amostras, via bootstrap, dos dados e construídos os intervalos da renda para cada uma;

- Partindo dos intervalos construídos, os limites superiores e inferiores de cada ano são ordenados, onde $W_{\text {sup }}(1)$ representa o maior limite superior de um determinado ano e $W_{\text {inf }}(200)$ o menor;

Sendo $W_{\text {sup }}(1+i)$ e $W_{\text {inf }}(200-i), 199 \geq i \geq 1$, encontra-se o valor de $i$ tal que $95 \%$ dos intervalos estimados das 200 amostras encontrem-se entre esses limites. Os valores encontrados correspondem aos limites das estimações considerando o intervalo de confiança de $95 \%$. 


\section{4 - BANCO DE DADOS E INSTRUMENTO}

\subsection{Banco de dados}

A base de dados utilizada foi a Pesquisa Nacional por Amostra de Domicílios (PNAD), que tem como finalidade a produção de informações básicas para o estudo do desenvolvimento socioeconômico do país. A pesquisa é elaborada e divulgada anualmente pelo Instituto Brasileiro de Geografia e Estatística, exceto nos anos de divulgação do Censo. O período analisado compreende os anos de 1996 a 2006 a exceção de 2000, ano em que a PNAD não é divulgada.

O salário dos empregados utilizado é o rendimento mensal em dinheiro proveniente do trabalho principal da semana de referência, deflacionado pelo IPCA médio do ano. Foram excluídas da amostra as observações que não informavam o valor da renda proveniente do trabalho. Como o objetivo deste trabalho é medir a renda potencial dos trabalhadores independentemente do número de horas trabalhadas, não se utilizou nenhuma medida de rendimento por hora trabalhada. Desse modo, possíveis distorções são evitadas, tal como assumir que profissionais que cobram por hora de trabalho tenham sua renda inflada enquanto, na verdade, eles conseguem trabalhar apenas poucas horas semanais - como é o caso muitas categorias de profissionais liberais.

A população abrangida na dissertação inclui apenas as pessoas em idade ativa, entre 22 e 60 anos. As pessoas que declararam terem nascido em Brasília antes da sua inauguração oficial em 1960 foram mantidas, visto já existirem cidades no perímetro do atual Distrito Federal. Além disso, como os estados de Rondônia, Acre, Amazonas, Roraima, Pará e Amapá só passaram a ser contemplados pela PNAD a partir de 2004, essas regiões foram excluídas da amostra.

Para construir o grupo de empregados bram consideradas todas as pessoas que se declararam empregadas e que possuíam remuneração. Desse modo, foram aceitas todas as classes de trabalho expostas na tabela 1 . 
Tabela 1: Distribuição das ocupações da força de trabalho

\begin{tabular}{lcccc}
\hline & 1996 & 1999 & 2001 & 2006 \\
\hline Empregado com carteira & $28.9 \%$ & $27.4 \%$ & $29.3 \%$ & $31.7 \%$ \\
Militar & $0.4 \%$ & $0.4 \%$ & $0.4 \%$ & $0.3 \%$ \\
Funcionário público estatutário & $6.3 \%$ & $6.2 \%$ & $6.1 \%$ & $6.3 \%$ \\
Outros Empregados sem carteira & $17.4 \%$ & $17.3 \%$ & $18.3 \%$ & $17.7 \%$ \\
Empregados sem declaração de carteira & $0.0 \%$ & $0.0 \%$ & $0.0 \%$ & $0.0 \%$ \\
Trabalhador doméstico com carteira & $1.6 \%$ & $1.9 \%$ & $2.0 \%$ & $2.1 \%$ \\
Trabalhador doméstico sem carteira & $5.7 \%$ & $5.6 \%$ & $5.8 \%$ & $5.5 \%$ \\
Trabalhador doméstico sem declaração de carteira & $0.0 \%$ & $0.0 \%$ & $0.0 \%$ & $0.0 \%$ \\
Conta- própria & $22.3 \%$ & $23.2 \%$ & $22.2 \%$ & $21.2 \%$ \\
Empregador & $3.7 \%$ & $4.1 \%$ & $4.2 \%$ & $4.5 \%$ \\
Trabalhador na produção para o próprio consumo & $4.3 \%$ & $4.5 \%$ & $3.9 \%$ & $4.5 \%$ \\
Trabalhador na construção para o próprio uso & $0.3 \%$ & $0.2 \%$ & $0.2 \%$ & $0.2 \%$ \\
Não remunerado & $9.1 \%$ & $9.3 \%$ & $7.7 \%$ & $6.1 \%$ \\
Sem declaração & $0.0 \%$ & $0.0 \%$ & $0.0 \%$ & $0.0 \%$ \\
\hline
\end{tabular}

O grupo dos desempregados foi construído de modo distinto do usual, considerando as pessoas que declararam não possuir um emprego independentemente de terem procurado trabalho ou não. De acordo com a metodologia usualmente utilizada para medir o desemprego, apenas os não empregados que procuraram emprego são considerados desempregados. Esta mudança é necessária visto que alguns desempregados podem desistir de procurar emprego sem que isso implique que eles não possuam uma renda potencial. Este é o caso de trabalhadores qualificados que decidem parar de trabalhar por um tempo ou de alunos de graduação que postergam a entrada no mercado de trabalho para fazer um curso de pósgraduação.

\begin{tabular}{|c|c|c|c|}
\hline & Homens & Mulheres & Total \\
\hline 1996 & $7.4 \%$ & $39.0 \%$ & $24.0 \%$ \\
\hline 1997 & $7.4 \%$ & $37.7 \%$ & $23.2 \%$ \\
\hline 1998 & $8.4 \%$ & $38.5 \%$ & $24.1 \%$ \\
\hline 1999 & $8.8 \%$ & $36.9 \%$ & $23.5 \%$ \\
\hline 2001 & $8.7 \%$ & $36.2 \%$ & $23.1 \%$ \\
\hline 2002 & $8.7 \%$ & $34.5 \%$ & $22.1 \%$ \\
\hline 2003 & $9.2 \%$ & $34.5 \%$ & $22.4 \%$ \\
\hline 2004 & $9.2 \%$ & $33.8 \%$ & $22.1 \%$ \\
\hline 2005 & $8.8 \%$ & $32.2 \%$ & $21.0 \%$ \\
\hline 2006 & $8.7 \%$ & $31.2 \%$ & $20.5 \%$ \\
\hline
\end{tabular}


Por conta da elevada taxa de desemprego feminino, não é possível encontrar o limite superior para os intervalos da distribuição acumulada $F(W / X)$ das mulheres para percentuais superiores a 61\% - notadamente por conta do desemprego de 1996. Além disso, dada a relação positiva encontrada entre o tamanho do intervalo e a taxa de desemprego, os intervalos para $F(W / X)<61 \%$ são bastante grandes, impossibilitando qualquer tipo de conclusão acerca do comportamento da desigualdade. Esse é o principal fator que justifica a exclusão das mulheres da população de interesse deste estudo.

Já as pessoas que declararam possuir emprego, mas não possuíam rendimentos, receberam um tratamento diferenciado. Para a construção da probabilidade de conseguir emprego, elas foram classificadas como empregadas. Todavia, para a construção da distribuição acumulada dos salários dos empregados esta parcela foi desconsiderada, sendo considerado que a distribuição da renda destes trabalhadores não era diferente da apresentada pelos empregados.

Partindo dos dados disponibilizados pela PNAD, é possível observar que a renda média dos trabalhadores recuou entre 1996 e 2002, recuperando-se parcialmente nos anos seguintes (figura 1).

Figura 1: Rendimento mensal do trabalho de empregados, empregadores e conta própria - em R \$ de set/2007

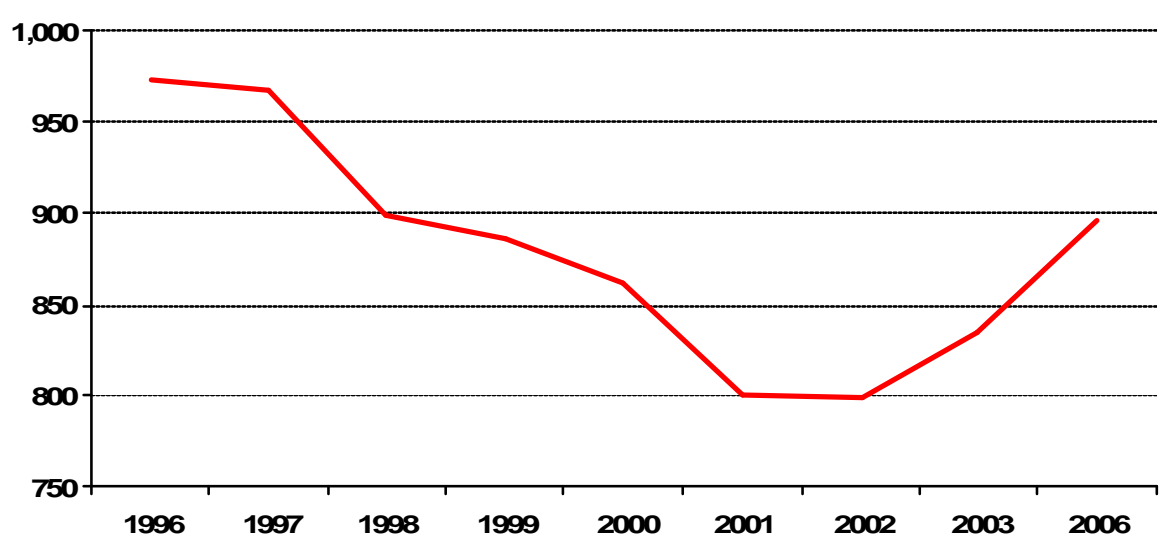

Fonte: Instituto Brasileiro de Geografia e Estatística, Pesquisa Nacional por Amostra de Domicílios

Todavia, a queda da renda média dos trabalhadores foi acompanhada de uma melhora dos indicadores de desigualdade de renda. O índice de Gini, divulgado pelo Instituto Brasileiro de Geografia e Estatística, demonstra um recuo continuado da desigualdade a partir de 1993 (figura 2). 
Figura 2 - Evolução do índice de Gini

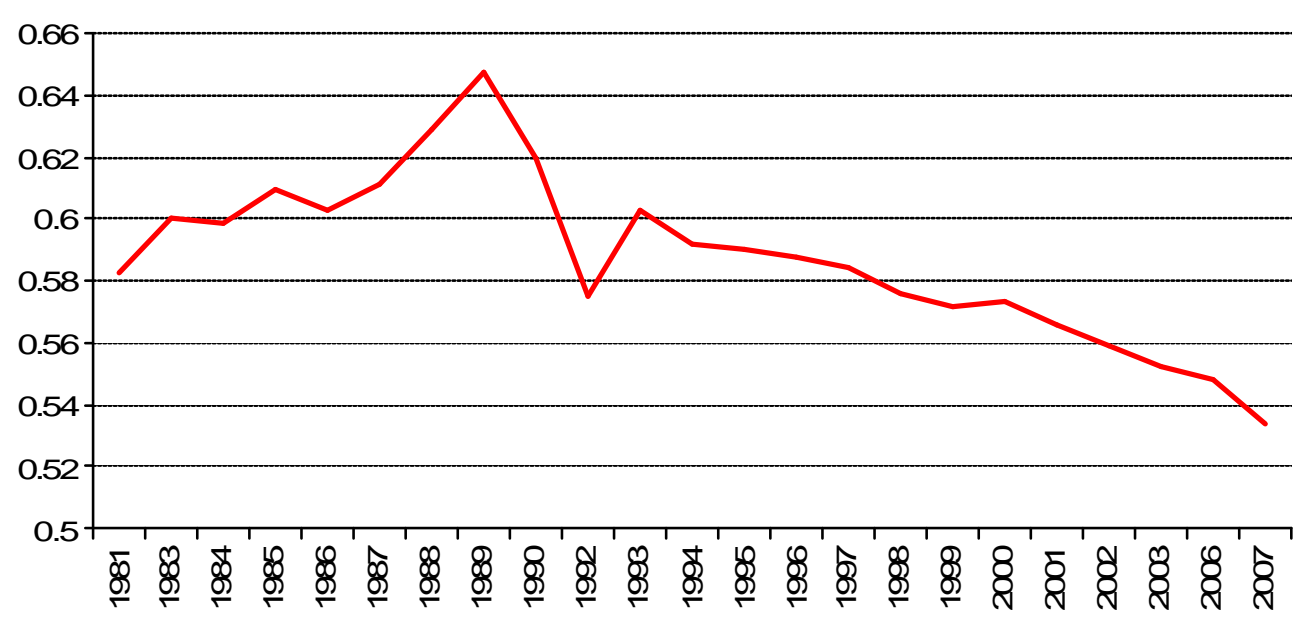

Fonte: Instituto Brasileiro de Geografia e Estatística, Pesquisa Nacional por Amostra de Domicílios

Os dados mostram também que tanto entre os empregados como entre os desempregados existe uma maior participação das mulheres, menor participação de brancos e aumento do nível de instrução. As magnitudes destas mudanças foram significativas entre as duas populações. Enquanto a participação de homens empregados recuou 3,2 p.p., entre os desempregados este recuo foi de $0,9 \%$. Já a participação de brancos na população empregada apresentou um recuo menor (de 6.9 pontos percentuais) em relação à população empregada (9.4 pontos percentuais), sendo que entre os desempregados a etnia mais representativa é a parda por uma significativa margem de diferença, enquanto que entre os empregados é a branca.

Por fim, observa-se que o perfil de escolaridade dos desempregados tem se aproximado do perfil dos empregados, com crescimento da participação de pessoas com 8 ou mais anos de estudo. Essa variável, todavia, esconde prováveis discrepâncias decorrentes da qualidade do ensino observado entre as populações empregada e desempregada. A mera aceitação da hipótese que os empregados apresentaram, em média, uma melhor qualidade de ensino e que esta diferença de qualidade se alterou no decorrer das últimas décadas já é argumento suficiente para justificar a existência de características não observáveis relevantes. 
Tabela 2 - Composição das populações empregadas e desempregadas por gênero, cor e escolaridade

\begin{tabular}{|c|c|c|c|c|c|c|c|c|}
\hline & \multicolumn{4}{|c|}{ Empregada } & \multicolumn{4}{|c|}{ Não empregada } \\
\hline & 1996 & 2001 & 2006 & Var 06/96 & 1996 & 2001 & 2006 & Var 06/96 \\
\hline Masculino & $62.0 \%$ & $60.4 \%$ & $58.8 \%$ & $-3.2 \%$ & $32.2 \%$ & $32.6 \%$ & $31.3 \%$ & $-0.9 \%$ \\
\hline Feminino & $38.0 \%$ & $39.6 \%$ & $41.2 \%$ & $3.2 \%$ & $67.9 \%$ & $67.4 \%$ & $68.8 \%$ & $0.9 \%$ \\
\hline Branca & $54.7 \%$ & $51.9 \%$ & $47.8 \%$ & $-6.9 \%$ & $49.7 \%$ & $44.8 \%$ & $40.3 \%$ & $-9.4 \%$ \\
\hline Preta & $6.7 \%$ & $6.4 \%$ & $8.2 \%$ & $1.6 \%$ & $6.5 \%$ & $6.7 \%$ & $8.4 \%$ & $1.9 \%$ \\
\hline Amarela & $0.4 \%$ & $0.4 \%$ & $0.4 \%$ & $0.1 \%$ & $0.4 \%$ & $0.4 \%$ & $0.4 \%$ & $0.0 \%$ \\
\hline Parda & $38.1 \%$ & $41.1 \%$ & $43.2 \%$ & $5.1 \%$ & $43.2 \%$ & $47.9 \%$ & $50.5 \%$ & $7.4 \%$ \\
\hline Indígena & $0.2 \%$ & $0.2 \%$ & $0.3 \%$ & $0.2 \%$ & $0.3 \%$ & $0.2 \%$ & $0.4 \%$ & $0.1 \%$ \\
\hline $\begin{array}{c}\text { Sem instrução e menos de } \\
1 \text { ano }\end{array}$ & $11.9 \%$ & $10.1 \%$ & $7.3 \%$ & $-4.6 \%$ & $18.4 \%$ & $14.7 \%$ & $11.9 \%$ & $-6.5 \%$ \\
\hline 1 a 3 anos & $13.9 \%$ & $12.2 \%$ & $9.6 \%$ & $-4.3 \%$ & $18.2 \%$ & $15.7 \%$ & $13.4 \%$ & $-4.8 \%$ \\
\hline 4 a 7 anos & $30.0 \%$ & $28.1 \%$ & $24.7 \%$ & $-5.3 \%$ & $32.8 \%$ & $32.3 \%$ & $28.5 \%$ & $-4.3 \%$ \\
\hline 8 a 10 anos & $15.2 \%$ & $15.4 \%$ & $15.4 \%$ & $0.3 \%$ & $13.8 \%$ & $15.2 \%$ & $15.7 \%$ & $1.9 \%$ \\
\hline 11 a 14 anos & $20.5 \%$ & $25.2 \%$ & $32.3 \%$ & $11.8 \%$ & $14.0 \%$ & $19.3 \%$ & $26.5 \%$ & $12.5 \%$ \\
\hline 15 anos ou mais & $8.5 \%$ & $9.0 \%$ & $10.6 \%$ & $2.1 \%$ & $2.7 \%$ & $2.9 \%$ & $3.8 \%$ & $1.1 \%$ \\
\hline
\end{tabular}

Tabela 3 - Taxa de participação na força de trabalho por grupo social

\begin{tabular}{cccc|c}
\hline & $\mathbf{1 9 9 6}$ & $\mathbf{2 0 0 1}$ & $\mathbf{2 0 0 6}$ & Var 06/96 \\
\hline Masculino & $92.6 \%$ & $91.3 \%$ & $91.3 \%$ & $-1.3 \%$ \\
Feminino & $61.0 \%$ & $63.8 \%$ & $68.8 \%$ & $7.8 \%$ \\
\hline Branco & $75.2 \%$ & $76.9 \%$ & $79.6 \%$ & $4.4 \%$ \\
Preto ou pardo & $77.2 \%$ & $76.9 \%$ & $79.4 \%$ & $2.2 \%$ \\
Outros & $77.6 \%$ & $76.5 \%$ & $79.3 \%$ & $1.7 \%$ \\
\hline Sem instrução e menos & $70.8 \%$ & $70.1 \%$ & $70.2 \%$ & $-0.6 \%$ \\
de 1 ano & $73.8 \%$ & $74.3 \%$ & $75.8 \%$ & $2.0 \%$ \\
1 a 3 anos & $74.3 \%$ & $75.0 \%$ & $77.1 \%$ & $2.8 \%$ \\
4 a 7 anos & $76.4 \%$ & $76.6 \%$ & $79.4 \%$ & $3.0 \%$ \\
8 a 10 anos & $80.9 \%$ & $81.4 \%$ & $83.2 \%$ & $2.4 \%$ \\
11 a 14 anos & $89.3 \%$ & $88.3 \%$ & $88.8 \%$ & $-0.5 \%$ \\
\hline 15 anos ou mais & & &
\end{tabular}




\subsection{Instrumentos}

Para a utilização das restrições de exclusão e monotonicidade será utilizado como instrumento o número de escolas por 1.000 habitantes no Estado em que o indivíduo vivia quando tinha 10 anos. Como para os indivíduos que migraram não há como verificar em que estado ele vivia quando tinha essa idade, foi assumido o número de escolas do seu estado natal. O percentual destes indivíduos representa aproximadamente $21 \%$ da amostra.

Tabela 4 - Unidades Escolares por 1000 habitantes

\begin{tabular}{|c|c|c|c|c|c|c|c|}
\hline Estado/Ano & 1939 & 1949 & 1959 & 1969 & 1979 & 1989 & 1999 \\
\hline Rondônia & & 1.20 & 1.44 & 1.54 & 2.44 & 2.74 & 2.23 \\
\hline Acre & 1.37 & 1.32 & 0.99 & 1.86 & 1.94 & 2.81 & 2.93 \\
\hline Amazonas & 1.45 & 1.01 & 1.63 & 1.78 & 1.94 & 2.02 & 1.75 \\
\hline Roraima & & 0.89 & 0.89 & 2.72 & 2.96 & 1.53 & 1.95 \\
\hline Pará & 1.22 & 1.82 & 1.69 & 1.64 & 1.83 & 2.14 & 2.25 \\
\hline Amapá & & 2.01 & 2.07 & 1.64 & 1.30 & 1.17 & 1.45 \\
\hline Maranhão & 0.61 & 0.64 & 0.81 & 1.68 & 2.32 & 2.53 & 2.49 \\
\hline Piauí & 0.59 & 0.76 & 1.11 & 1.75 & 3.21 & 3.32 & 2.91 \\
\hline Ceará & 0.82 & 1.30 & 2.07 & 2.36 & 3.67 & 2.27 & 1.70 \\
\hline Rio Grande do Norte & 0.85 & 1.19 & 2.13 & 2.51 & 2.47 & 2.09 & 1.62 \\
\hline Paraíba & 0.74 & 0.93 & 1.38 & 2.31 & 3.05 & 2.64 & 2.16 \\
\hline Pernambuco & 0.90 & 1.10 & 1.70 & 1.87 & 1.79 & 1.63 & 1.51 \\
\hline Alagoas & 0.73 & 0.83 & 1.30 & 1.72 & 1.29 & 1.46 & 1.43 \\
\hline Sergipe & 1.20 & 1.24 & 1.67 & 1.90 & 1.94 & 1.47 & 1.41 \\
\hline Bahia & 0.52 & 0.69 & 1.25 & 1.95 & 2.47 & 2.25 & 2.18 \\
\hline Minas Gerais & 0.78 & 1.23 & 1.36 & 1.57 & 1.47 & 1.24 & 0.94 \\
\hline Espírito Santo & 1.27 & 1.64 & 2.52 & 2.62 & 2.89 & 1.83 & 1.29 \\
\hline Rio de Janeiro + Guanabara & 0.91 & 0.82 & 0.84 & 0.75 & 0.62 & 0.59 & 0.67 \\
\hline São Paulo & 1.08 & 1.18 & 1.29 & 1.16 & 0.81 & 0.56 & 0.45 \\
\hline Paraná + Iquaçu & 1.31 & 0.92 & 1.51 & 1.90 & 1.86 & 1.53 & 0.93 \\
\hline Santa Catarina & 1.82 & 2.18 & 2.45 & 2.38 & 2.15 & 1.92 & 1.13 \\
\hline Rio Grande do Sul & 1.73 & 1.91 & 2.14 & 2.38 & 2.07 & 1.72 & 1.05 \\
\hline Mato Grosso + MS + Ponta Porã & 0.95 & 1.36 & 1.84 & 1.70 & 1.48 & 1.50 & 1.10 \\
\hline Goiás + Tocantins & 0.74 & 0.83 & 1.20 & 1.60 & 1.76 & 1.88 & 1.40 \\
\hline Brasília & & & 0.08 & 0.49 & 0.39 & 0.38 & 0.43 \\
\hline Brasil & 0.97 & 1.16 & 1.47 & 1.67 & 1.69 & 1.47 & 1.21 \\
\hline
\end{tabular}

O número de escolas disponíveis no estado em que o indivíduo morava quando estava em idade escolar está diretamente relacionado à distância média da escola às residências afetando o custo de mandar o filho a escola - além das opções dos pais sobre em que escola matricular - afetando o benefício. Por conta disso, é de se esperar que um maior número de escolas por 1.000 habitantes em um estado resulte na melhora da relação custo/benefício e no aumento do investimento na educação do filho. Assim, é de se esperar que estados com número mais elevado de escolas apresentem um nível médio de escolaridade mais elevado.

A idéia por trás deste instrumento é encontrar uma variável relacionada à auto-seleção individual. Mais especificamente, se dois indivíduos provenientes de estados com diferentes números de escolas por 1.000 habitantes apresentam o mesmo nível educacional, espera-se que o indivíduo do estado com menos escolas apresente características não observáveis mais "favoráveis" que o outro, existindo uma auto-seleção positiva. 
Por exemplo, é de se esperar que as pessoas com 4 a 7 anos de estudo de Rondônia que tinham 10 anos em 1969 apresentem características não observáveis mais positivas que igual grupo de Roraima, onde o número de escolas por 1.000 habitantes era maior. Este componente de auto-seleção, por sua vez, deve estar correlacionado com a capacidade do indivíduo de conseguir trabalho.

Por conta disso, é de se esperar que o número de escolas por 1.000 habitantes seja positivamente correlacionado com o desemprego uma vez controlado os anos de estudo (tabela 5).

Tabela 5- Correlação do desemprego com número de escolas por 1.000 habitantes para cada grupo de escolaridade

\begin{tabular}{|c|c|c|c|c|c|c|c|c|c|c|c|}
\hline & 1996 & 1997 & 1998 & 1999 & 2001 & 2002 & 2003 & 2004 & 2005 & 2006 & Média \\
\hline $\begin{array}{l}\text { Sem instrução e menos } \\
\text { de } 1 \text { ano }\end{array}$ & -0.03 & -0.02 & -0.06 & -0.07 & -0.02 & -0.07 & -0.03 & -0.11 & -0.09 & -0.12 & -0.09 \\
\hline 1 a 3 anos & 0.34 & 0.31 & 0.32 & 0.37 & 0.39 & 0.42 & 0.33 & 0.38 & 0.40 & 0.37 & 0.33 \\
\hline 4 a 7 anos & 0.52 & 0.53 & 0.54 & 0.58 & 0.58 & 0.57 & 0.58 & 0.58 & 0.59 & 0.56 & 0.54 \\
\hline 8 a 10 anos & 0.51 & 0.50 & 0.50 & 0.51 & 0.53 & 0.54 & 0.55 & 0.47 & 0.53 & 0.53 & 0.50 \\
\hline 11 a 14 anos & 0.42 & 0.45 & 0.41 & 0.44 & 0.44 & 0.46 & 0.46 & 0.45 & 0.47 & 0.43 & 0.43 \\
\hline 15 anos ou mais & 0.32 & 0.38 & 0.34 & 0.39 & 0.38 & 0.39 & 0.43 & 0.43 & 0.43 & 0.35 & 0.37 \\
\hline $\begin{array}{l}\text { Não determinados e } \\
\text { sem declaracão }\end{array}$ & 0.13 & 0.24 & 0.02 & 0.21 & -0.09 & 0.16 & -0.04 & 0.00 & 0.36 & -0.12 & 0.07 \\
\hline Media anual & 0.35 & 0.36 & 0.35 & 0.38 & 0.41 & 0.41 & 0.40 & 0.39 & 0.42 & 0.40 & 0.36 \\
\hline
\end{tabular}

Dadas as condições para a validade das restrições de exclusão e monotonicidade, é necessário que o instrumento esteja relacionado à probabilidade de se estar empregado, visto que é através desse canal que o instrumento tem poder para afetar os limites superiores e inferiores das distribuições. Posto de outra forma, controlando a escolaridade, espera-se que as pessoas cujo estado apresentava um número mais elevado de escolas por 1.000 habitantes apresentem uma maior probabilidade de desemprego.

Todavia, como o serviço público de educação tem se tornado de uso apenas daqueles incapazes de arcar com os custos de escolas particulares, é de se esperar que esta variável não seja correlacionada com a entrada no mercado de trabalho, desemprego e rendimentos dos trabalhadores oriundos das classes mais abastadas. Caso este seja realmente o caso, apenas os intervalos das distribuições dos mais pobres são reduzidos com a adoção deste instrumento. 


\section{5 - ESTIMAÇÃO E RESULTADOS}

\section{1 - Estimação}

Para a estimação dos intervalos, foram executadas as seguintes etapas. Inicialmente, foram construídas as probabilidades de um indivíduo da população estar empregado $P(z=1)$. Nesta etapa, foram utilizadas todas as pessoas que se intitularam empregadas dentro do contingente abrangido. A probabilidade de um indivíduo estar empregado é definida como:

$$
\hat{P}(z=1)=\frac{\sum_{1}^{N} I(z=1)}{N}
$$

onde I é um indicador que assume valor um quando é válida a condição imposta e zero caso contrário. Ou seja, a probabilidade de estar empregado é igual à somatória de todas as pessoas empregadas dividido pelo total de pessoas. Concomitantemente, construiu-se a distribuição de renda. Nesta etapa foram excluídas as pessoas que se intitularam empregadas, mas que não informaram a renda. A probabilidade acumulada dos empregados com renda de até $\mathrm{W}, F(W / Z=1)$, é definida como:

$$
\hat{F}(W / z=1, \bar{x})=\frac{\sum_{1}^{N} I\left(W_{i} \leq W\right)}{N}
$$

Uma vez construídas as probabilidades e a distribuição da renda dos empregados, é possível encontrar os intervalos para a distribuição populacional $F(W)$, contanto que a probabilidade de interesse da distribuição acumulada não exceda a probabilidade de estar desempregado $(1-P(z=1))$. O intervalo para a probabilidade acumulada é estimado em duas etapas. Primeiro é preciso encontrar os limites para $F(W / z=1)$ para, posteriormente, encontrar o salário respectivo às probabilidades encontradas. O intervalo de $F(W / z=1)$ é definido como: 


$$
\begin{aligned}
& \hat{F}(W / z=1) \leq \frac{F(W)}{\hat{P}(z=1)} \\
& \hat{F}(W / z=1) \geq 1-\frac{1-F(W)}{\hat{P}(z=1)}
\end{aligned}
$$

onde $F(W)$ é a probabilidade acumulada da distribuição definida a priori. A obtenção dos limites da probabilidade acumulada $F(W / z=1)$ e o cálculo da sua inversa $W \leq F^{-1}($. fornece os limites para a renda sem que seja utilizada qualquer hipótese sobre a distribuição da renda potencial.

A restrição da mediana possibilita diminuir o tamanho do intervalo da distribuição, ao impor que apenas metade dos desempregados pode ter salários potenciais superiores a renda da mediana dos empregados. Por conta disso, esta restrição se torna ativa apenas para a metade superior da distribuição de renda potencial. O método de estimação dos intervalos para a mediana e para o quartil mais elevado da distribuição é definido como:

$$
\begin{aligned}
& \hat{F}(W / z=1) \leq \frac{F(W / z=1)+(P(z=1)-1)}{\hat{P}(z=1)} \\
& \hat{F}(W / z=1) \geq \frac{F(W / z=1)+0.5(P(z=1)-1)}{\hat{P}(z=1)}
\end{aligned}
$$

Com a imposição desta restrição, o limite superior dos intervalos é reduzido. Esse resultado possui implicação direta sobre a desigualdade de renda. A medida de desigualdade utilizada foi a razão interquartil, sendo considerados dois casos: um com a restrição da mediana e outro sem a restrição da mediana. Para tanto, foi necessário calcular intervalos para os rendimentos do primeiro e quarto quartis, de rendimentos mais baixos e de rendas mais elevadas, respectivamente, utilizando as probabilidades encontradas.

Dessa forma, o limite superior da desigualdade é a razão do limite superior do intervalo dos $25 \%$ mais ricos sobre o limite inferior do intervalo dos $25 \%$ mais pobres. De maneira análoga é construído o limite inferior da desigualdade. Já a restrição da mediana 
reduz o limite superior do quartil mais rico e, com isso, reduz o limite superior da desigualdade.

\section{2- Resultados}

Os resultados obtidos foram divididos em dois segmentos. O primeiro contém os intervalos para as medianas dos rendimentos, utilizando as restrições da mediana, exclusão e monotonicidade. Como a restrição da dominância estocástica, para o caso da mediana unicamente, é equivalente a restrição da mediana, ela não é apresentada. O segundo segmento trata da desigualdade considerando apenas a restrição da mediana e da dominância estocástica. Como o exame da mediana dos rendimentos apontou a não validade das restrições de exclusão e monotonicidade, não serão apresentados os resultados da desigualdade dos rendimentos sob estas duas restrições.

Uma vez estabelecidos os menores intervalos que englobam as possíveis distribuições de renda nos diferentes anos será possível analisar o comportamento da desigualdade de renda no Brasil. Para constatar que a desigualdade recuou, será preciso que o limite inferior do intervalo de 1996 seja superior ao limite superior de 2006. Caso o contrário se verifique, o limite inferior de 2006 seja maior que o limite superior de 1996, terá ocorrido um aumento da desigualdade. Caso nenhuma destas combinações se verifique o resultado não será conclusivo.

Para os casos em que se verificou queda ou crescimento da desigualdade de renda e da mediana dos rendimentos foram construídos intervalos de confiança tal como descrito na parte metodológica. Esse caso é verificado com a mediana dos rendimentos utilizando a restrição da mediana e com a desigualdade de renda sob a restrição da monotonicidade.

\subsection{1 - Mediana dos rendimentos}

\subsubsection{1 - Mediana dos rendimentos sob a restrição da mediana}

Os primeiros resultados foram obtidos sem a utilização de nenhuma restrição sobre a distribuição da renda. $\mathrm{Na}$ figura 3, esses resultados são representados pelas linhas não tracejadas. A linha superior representa o maior valor que a renda mediana pode apresentar controlando o viés de seleção enquanto a linha inferior representa o menor valor. A análise dos resultados mostra que em nenhum momento os limites superiores dos rendimentos de qualquer ano encontram-se abaixo dos limites inferiores de outro ano, não sendo possível afirmar que houve queda da desigualdade. 
Utilizando a hipótese da mediana, o limite superior do intervalo é reduzido sem que seja alterado o limite inferior. Na figura 3, essa mudança é representada pela linha tracejada, que passa a representar o novo limite superior da mediana. Sob esta primeira restrição, é possível afirmar que a mediana dos rendimentos de 1996, 1997 e de 2006 eram superiores às medianas entre 2002 e 2004.

Figura 3 - Intervalo para a mediana da renda masculina



Para constatar se a queda da mediana dos rendimentos sob a restrição é estatisticamente significante, foram construídos intervalos de confiança para os limites inferior e superior sob a hipótese da mediana. Na figura 4 são apresentados os resultados encontrados. A área azul representa o intervalo de confiança do limite superior sob a restrição da mediana e a área vermelha o limite inferior. O modo de interpretação dos resultados permanece o mesmo, ou seja, o ponto mínimo do intervalo de confiança do limite inferior de um determinado ano tem que ser maior que o ponto máximo do limite superior sob a restrição da mediana de outro ano para que se possa afirmar que houve queda ou aumento da mediana dos rendimentos.

Os resultados encontrados apontam que a mediana dos rendimentos de 1996 foi superior a de todo período de 2002 e 2004 e que a mediana de 2006 foi maior que a de 2002 . 
Figura 4 - Intervalos de confiança para a mediana da renda masculina sob restrição da mediana

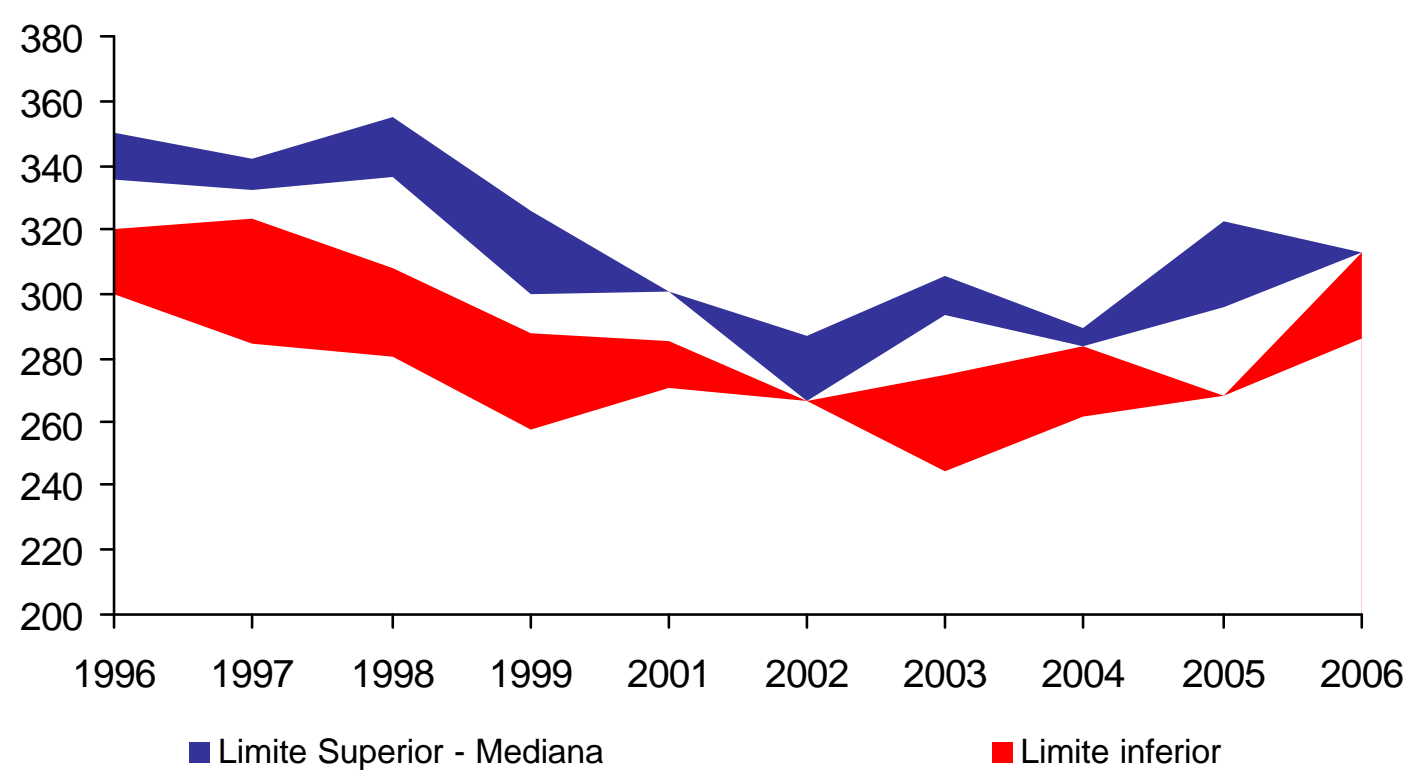

\begin{tabular}{|c|c|c|c|c|c|c|c|c|c|c|c|}
\hline Limite do bound & $\begin{array}{l}\text { Intervalo de } \\
\text { confiança }\end{array}$ & 1996 & 1997 & 1998 & 1999 & 2001 & 2002 & 2003 & 2004 & 2005 & 2006 \\
\hline \multirow{2}{*}{$\begin{array}{l}\text { Restrição da mediana } \\
\text { (limite superior) }\end{array}$} & superior & 350 & 342 & 355 & 326 & 301 & 287 & 306 & 290 & 323 & 313 \\
\hline & inferior & 336 & 333 & 337 & 300 & 301 & 267 & 294 & 284 & 296 & 313 \\
\hline \multirow{2}{*}{ Limite inferior } & superior & 320 & 323 & 309 & 288 & 286 & 267 & 275 & 284 & 269 & 313 \\
\hline & inferior & 300 & 285 & 280 & 257 & 271 & 267 & 245 & 261 & 269 & 287 \\
\hline
\end{tabular}

\subsubsection{2 - Mediana dos rendimentos sob restrição da exclusão}

Conforme apresentado na seção metodológica, a imposição da restrição da exclusão e da monotonicidade necessita da combinação do instrumento "número de escolas por 1.000 habitantes" com o número de anos de estudo, ou seja, é preciso que o instrumento seja aplicado em grupos que apresentem o mesmo número de anos de ensino. Por conta disso serão estimados os limites para a mediana para cada grupo de anos de estudo e, posteriormente, apresentados a média ponderada dos limites superior e inferior.

Os resultados obtidos sob a restrição da exclusão atestam a não validade da hipótese de independência da distribuição de renda em relação ao instrumento. Os limites inferiores de todos os anos encontram-se substancialmente acima dos limites superiores de cada período, ou seja, os limites inferiores encontrados para alguns grupos de pessoas com igual "número de escolas por 1.000 habitantes" eram substancialmente elevados, enquanto os limites superiores de outros grupos eram bastante baixos. Conforme descrito anteriormente, muito embora o não cruzamento dos intervalos de confiança não garanta a validade da hipótese de exclusão, o cruzamento dos limites atesta a não validade da mesma. 
Este resultado já era esperado previamente, pois a hipótese necessária para a utilização desta restrição requer que a distribuição da renda populacional seja igual para todos os grupos que apresentam igual número de escolas por 1000 habitantes. Conforme discutido na seção metodológica, acredita-se na existência de uma correlação entre a renda e o instrumento, hipótese esta que se confirmada implica na não validade da restrição da exclusão. O passo seguinte é utilizar o instrumento para testar a restrição da mediana.

\subsubsection{3 - Mediana sob restrição da monotonicidade}

Os resultados obtidos sob a restrição da monotonicidade atestam a não validade da hipótese de dominância da distribuição de renda em relação ao instrumento. Isso porque se observa que o intervalo não se reduziu, mas que apenas se deslocou para cima (figura 5). Comparando os limites apresentados abaixo com os do caso geral (figura 3 ) observa-se uma elevação do limite superior, inclusive quando a hipótese da monotonicidade é combinada com a da mediana.

Figura 5 - Mediana dos rendimentos masculinos sob restrição da monotonicidade

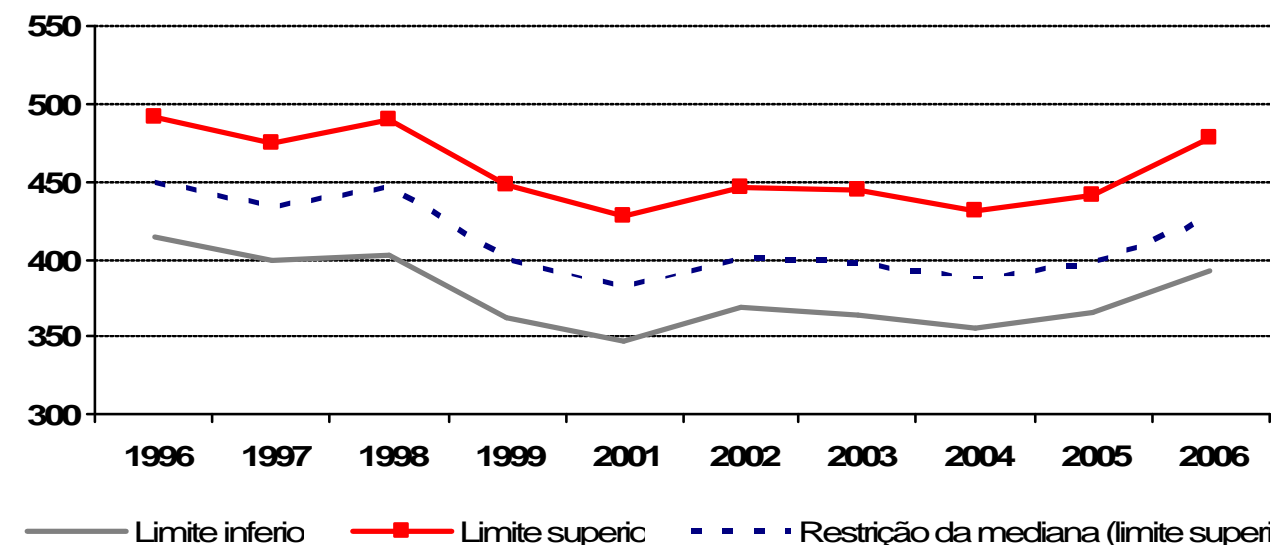

\begin{tabular}{lcccccccccc}
\hline & $\mathbf{1 9 9 6}$ & $\mathbf{1 9 9 7}$ & $\mathbf{1 9 9 8}$ & $\mathbf{1 9 9 9}$ & $\mathbf{2 0 0 1}$ & $\mathbf{2 0 0 2}$ & $\mathbf{2 0 0 3}$ & $\mathbf{2 0 0 4}$ & $\mathbf{2 0 0 5}$ & $\mathbf{2 0 0 6}$ \\
\hline Limite superior & 491 & 475 & 490 & 449 & 428 & 447 & 444 & 431 & 442 & 478 \\
Limite inferior & 415 & 401 & 404 & 362 & 347 & 368 & 363 & 355 & 365 & 394 \\
$\begin{array}{l}\text { Restrição da mediana } \\
\text { (limite superior) }\end{array}$ & 449 & 435 & 447 & 402 & 382 & 402 & 398 & 389 & 398 & 427 \\
\hline
\end{tabular}

Os resultados encontrados sob a restrição da exclusão e da mediana atestam a não validade da utilização do número de escolas por mil habitantes como instrumento. De fato, pode-se inferir que, embora o instrumento possa ser válido para parcelas mais pobres da população (em função da elevação do limite inferior da mediana sob a restrição da 
monotonicidade), os segmentos mais ricos seriam pouco ou nada influenciados pela quantidade de escolas. Todavia, devido à baixa influência do número de escolas por mil habitantes sobre as classes mais ricas e a possibilidade de correlação deste instrumento com outras variáveis socioeconômicas, a elevação do limite superior dos intervalos deve decorrer de alguma outra correlação não observada e que atua no sentido contrário do pretendido.

Para utilizar a restrição da monotonicidade seria necessário encontrar um instrumento que estivesse correlacionado com toda a população, e não apenas com uma parte. Neste caso, seria possível observar uma redução do limite superior acompanhada de uma elevação do limite inferior para os intervalos.

\subsection{2 - Desigualdade dos rendimentos sob restrição da mediana}

A desigualdade de renda medida é a razão entre a renda do primeiro e quarto quartis (o valor da renda do quartil mais rico dividido pela renda do quartil mais pobre), de modo que quanto maior for a razão mais desigual será a distribuição de renda. Desta forma, o limite superior da desigualdade captura a maior desigualdade de renda possível, enquanto o limite inferior mede a menor desigualdade. Já a restrição da mediana diminui o limite superior da desigualdade, de forma que o limite superior sob esta desigualdade nunca será maior que o limite superior sem a utilização da mesma.

\subsubsection{1 - Desigualdade dos rendimentos sob restrição da mediana}

A análise dos resultados da desigualdade de renda é bastante similar a análise da mediana. Na figura 6 são apresentados os resultados encontrados. As linhas não tracejadas representam os limites das desigualdades de renda de cada ano sem a utilização de qualquer restrição sobre a distribuição de renda. A linha superior representa o quadro de maior desigualdade de renda enquanto a linha inferior representa a menor desigualdade. Já a linha tracejada representa o novo limite superior sob a restrição da mediana, sendo que sob essa restrição o limite inferior não se altera.

Os resultados encontrados não possibilitam afirmar que a desigualdade de renda caiu para qualquer período analisado, muito embora o intervalo da desigualdade tenha se estreitado a ponto de quase possibilitar uma conclusão. A restrição da mediana reduziu o limite superior da desigualdade, mas não a ponto de possibilitar que se afirme que a desigualdade caiu. 
Figura 6 - Razão interquartil dos rendimentos masculinos

$\begin{array}{rllllllllllll} & \\ \end{array}$

\subsubsection{2 - Desigualdade sob restrição da dominância estocástica}

Sob a restrição da dominância estocástica a melhor distribuição da renda potencial é igual à distribuição de renda dos empregados, o que implica que a distribuição de renda dos desempregados não é melhor que a distribuição de renda dos empregados. Em função disso, na distribuição dos desempregados os limites superiores dos intervalos do primeiro e quarto quartis são iguais ao primeiro e quarto quartis da distribuição de renda dos empregados, enquanto os limites inferiores se mantêm.

Os resultados encontrados (figura 7) mostram que houve queda da desigualdade de renda sob a restrição da dominância estocástica, visto que o limite superior do intervalo de 2006 é menor que os limites inferiores observados entre 1996 e 1998. Já em relação ao biênio 2001/02 não é possível afirmar que houve queda, muito embora o limite inferior destes anos seja bem próximo ao limite superior de 2006. 
Figura 7 - Razão interquartil dos rendimentos masculinos sob restrição da dominância estocástica

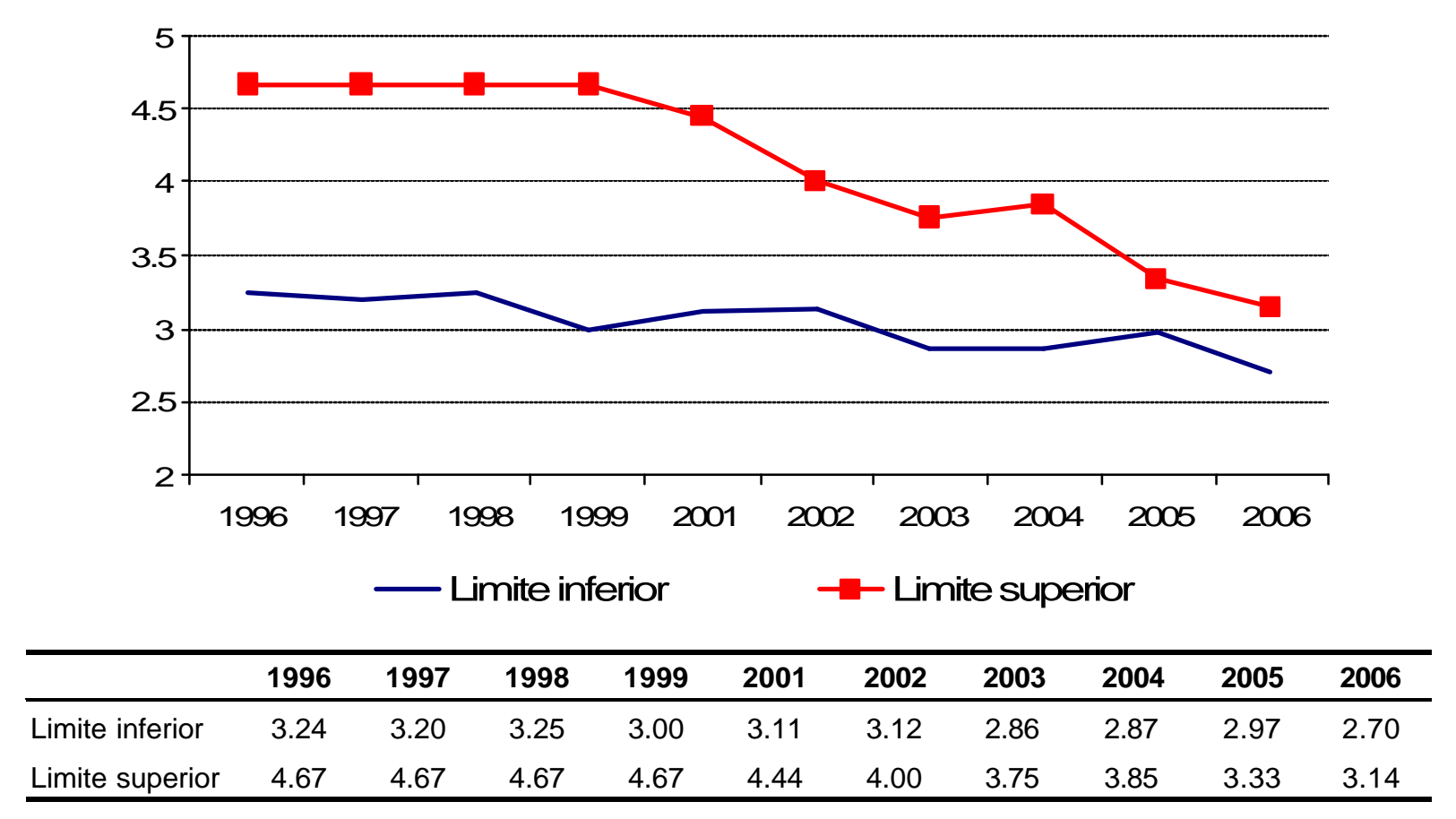

Para constatar se a queda da desigualdade sob a restrição é estatisticamente significante, foram construídos intervalos de confiança para os limites inferior e superior. $\mathrm{Na}$ figura 8 são apresentados os resultados encontrados, onde a área azul representa o intervalo de confiança do limite superior sob a restrição da mediana e a área vermelha o limite inferior. $\mathrm{O}$ modo de interpretação dos resultados permanece o mesmo, ou seja, o ponto mínimo do intervalo de confiança do limite inferior de um determinado ano tem que ser maior que o ponto máximo do limite superior de outro ano para que se possa afirmar que houve queda ou aumento da mediana dos rendimentos. Os resultados encontrados confirmam que houve queda da desigualdade em 2006 em relação ao período de 1996 a 1998 (figura 8). 
Figura 8 - Intervalo de confiança da razão interquartil dos rendimentos sob restrição da dominância estocástica

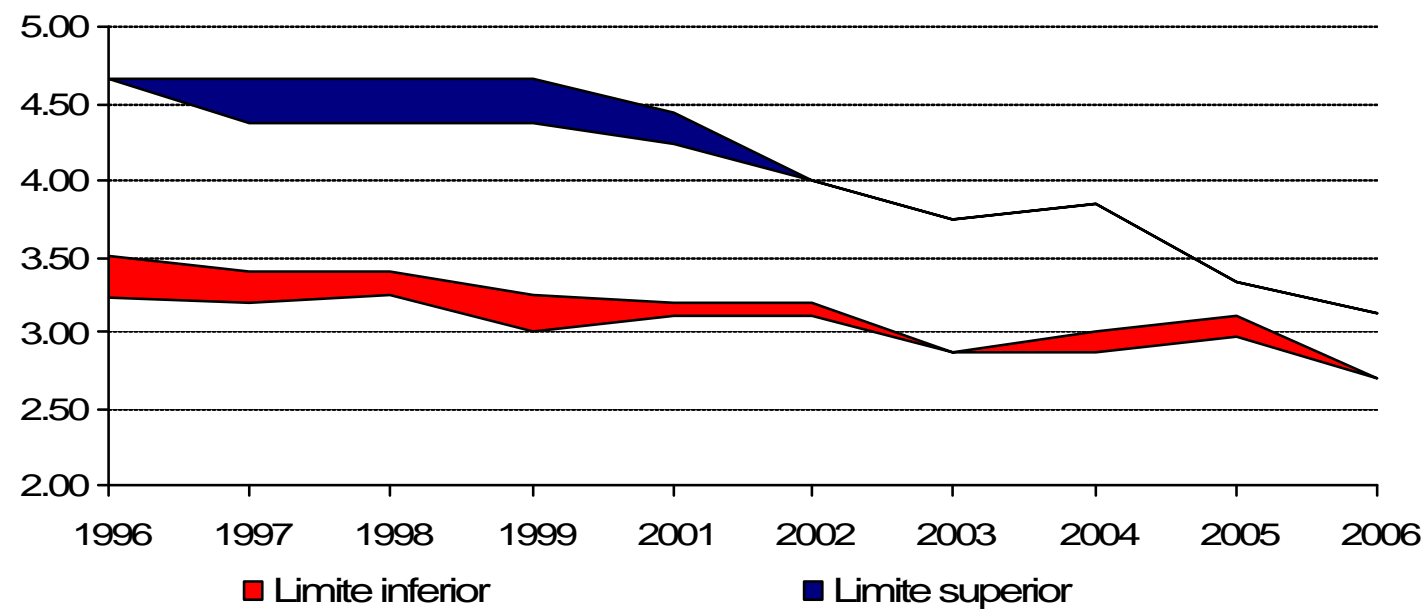

\begin{tabular}{lccccccccccc}
\hline & $\begin{array}{l}\text { Intervalo de } \\
\text { conf. }\end{array}$ & $\mathbf{1 9 9 6}$ & $\mathbf{1 9 9 7}$ & $\mathbf{1 9 9 8}$ & $\mathbf{1 9 9 9}$ & $\mathbf{2 0 0 1}$ & $\mathbf{2 0 0 2}$ & $\mathbf{2 0 0 3}$ & $\mathbf{2 0 0 4}$ & $\mathbf{2 0 0 5}$ & $\mathbf{2 0 0 6}$ \\
\hline \multirow{2}{*}{ Limite inferior } & superior & 3.51 & 3.40 & 3.40 & 3.25 & 3.20 & 3.20 & 2.86 & 3.00 & 3.13 & 2.70 \\
& inferior & 3.24 & 3.20 & 3.25 & 3.00 & 3.11 & 3.12 & 2.86 & 2.87 & 2.97 & 2.70 \\
& superior & 4.67 & 4.67 & 4.67 & 4.67 & 4.44 & 4.00 & 3.75 & 3.85 & 3.33 & 3.14 \\
Limite superior & inferior & 4.67 & 4.38 & 4.38 & 4.38 & 4.23 & 4.00 & 3.75 & 3.85 & 3.33 & 3.14 \\
\hline
\end{tabular}

Figura 9 - Intervalo de confiança dos limites superior e inferior dos rendimentos do primeiro e quarto quartis sob restrição da dominância estocástica

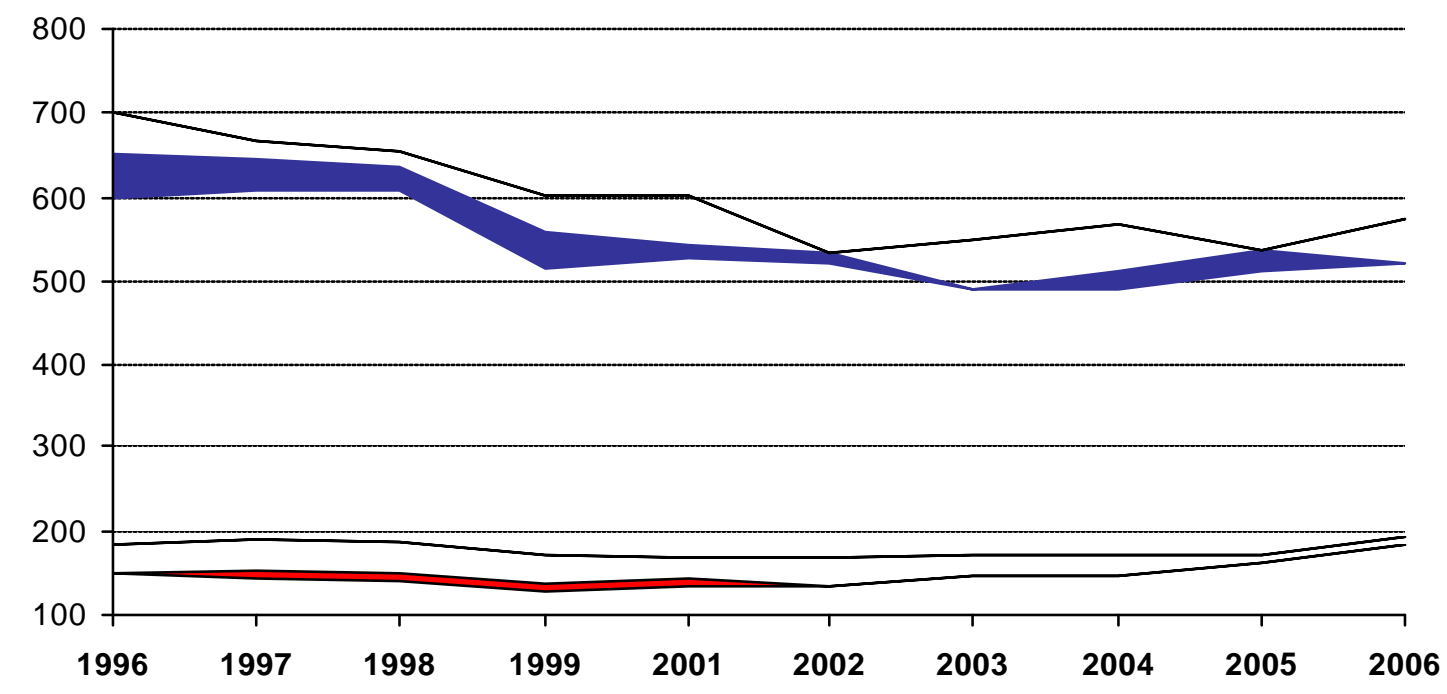

$\square 25 \%$ - limite inferior $\square 25 \%$ - limite superior $\quad \square 75 \%$ - limite inferior $\square 75 \%$ - limite superior 


\section{6 - CONCLUSÃO}

A desigualdade de renda é um dos principais indicadores utilizados para investigar o bem estar de uma população, existindo um amplo leque de possíveis métodos para medida-la. Usualmente, o estudo da desigualdade se concentra na renda das pessoas empregadas, assumindo que o nível de desigualdade desta parcela da população é uma medida válida para a população como um todo.

Todavia, a desigualdade da renda dos empregados pode levar a interpretações enganosas acerca do bem estar populacional em função do viés de seleção, que surge ao não se considerar os desempregados na análise. Esse problema acontece quando, por exemplo, trabalhadores bem remunerados são demitidos, provocando simultaneamente um aumento do desemprego e uma homogeneização da massa de trabalhadores empregada. Nessa situação, muito embora se verifique a piora na condição de alguns trabalhadores sem a melhora de outros, as medidas usuais de desigualdade de renda apontariam para uma melhora da distribuição.

Em função destas limitações das medidas de desigualdade de renda usuais, este estudo utilizou uma metodologia não paramétrica, desenvolvida por Manski (1994) e utilizada em Blundell et al. (2007; p. 323-363), para investigar a desigualdade de renda no Brasil entre 1996 e 2006. O método utiliza uma medida de renda potencial, que considera tanto a renda dos trabalhadores como também a potencial renda que os desempregados possuem (ou seja, quanto o desempregado poderia receber caso estivesse trabalhando). Dessa forma, incluem-se os desempregados na análise da desigualdade de renda e corrige-se o problema de seleção. Adicionalmente, foi analisado o comportamento da mediana dos rendimentos potenciais da população.

Para testar a metodologia, foi investigado o comportamento da mediana dos rendimentos entre 1996 e 2006 considerando dois cenários, um sem a utilização de restrições e outro utilizando apenas a restrição da mediana, que neste caso produz os mesmos resultados da restrição da dominância estocástica. Já as restrições de exclusão e da monotonicidade não foram consideradas devido à constatação da não validade das hipóteses estatísticas necessárias. Adicionalmente, foram construídos intervalos de confiança de 95\% para os limites inferior e superior sob a restrição da mediana. Os resultados obtidos sem a utilização de restrições não permitem afirmar se houve crescimento ou queda da mediana dos 
rendimentos. Já sob a restrição da mediana se observou queda em 2002 e 2004 em relação a 1996 e também que a mediana dos rendimentos de 2006 era superior a de 2002.

Para a análise da desigualdade foram considerados três cenários: sem restrições, sob restrição da mediana e sob restrição da dominância estocástica. A validade dos resultados encontrados utilizando as restrições da mediana e da dominância estocástica depende unicamente da aceitação das premissas, não existindo nenhuma restrição estatística para utilizá- las. Já os resultados obtidos sob as restrições de exclusão e de monotonicidade foram descartados por não atenderem aos requisitos estatísticos descritos na seção metodológica.

Os resultados encontrados sem a utilização de restrições ou sob a restrição da mediana não permitem afirmar que houve um recuo da desigualdade de renda da população, muito embora o limite superior do intervalo para a desigualdade de 2006 esteja bastante próximo do limite inferior de 1996 (caso fosse inferior seria possível afirmar que houve queda da desigualdade). É importante frisar que o fato de não ter sido observado uma queda da desigualdade de renda não implica que a distribuição se manteve constante ao longo de todo o período ou que as diferenças encontradas são estatisticamente iguais a zero.

Já sob a restrição da dominância estocástica constata-se um recuo da desigualdade de renda dos trabalhadores em 2006 frente os anos de 1996 a 1998. Isso implica que a distribuição de renda potencial da população em idade ativa apresentou uma melhora, contanto que se assuma que a distribuição de renda potencial dos desempregados é, na melhor das hipóteses, tão boa quanto à dos empregados.

Novos estudos podem ser feitos utilizando-se metodologias semelhantes à utilizada neste estudo para complementar a análise da distribuição de renda populacional controlando o viés de seleção. Novos instrumentos podem ser testados para reduzir os intervalos utilizando as restrições da mediana e/ou da exclusão. Outra alternativa é analisar a renda potencial familiar per capita, utilizando como restrição a hipótese que a renda potencial de um desempregado não supera a renda do trabalhador melhor remunerado na família. 


\section{BIBLIOGRAFIA}

Agostinho, C. S.; Turra, C. M.; Wajnman, S. Estrutura Domiciliar e Distribuição da Renda Familiar no Brasil. In: M. N. F. Ricardo Paes De Barros, Gabriel Ulyssea (Ed.). Desigualdade de Renda no Brasil: uma análise da queda recente. Brasília: IPEA, v.1, 2007. Estrutura Domiciliar e Distribuição da Renda Familiar no Brasil

Ahn, H.; J. L. Powell. Semiparametric Estimation of Censored Selection Models with a Nonparametric Selection Mechanism. Journal of Econometrics, v.58, p.p. 3-29. 1993.

Azevedo, J. P. Avaliando a Significância Estatística da Queda na Desigualdade no Brasil. In: M. N. F. Ricardo Paes De Barros, Gabriel Ulyssea (Ed.). Desigualdade de Renda no Brasil: uma análise da queda recente. Brasília: IPEA, v.1, 2007. Avaliando a Significância Estatística da Queda na Desigualdade no Brasil

Barros, R.P. ; Carvalho, M. ; Franco, S. S. O. ; Mendonça, R Determinantes Imediatos da Queda da Desigualdade de Renda Brasileira. In: M. N. F. Ricardo Paes De Barros, Gabriel Ulyssea (Ed.). Desigualdade de Renda no Brasil: uma análise da queda recente. Brasília: IPEA, v.1, 2007. Determinantes Imediatos da Queda da Desigualdade de Renda Brasileira

Barros, R. P.; Carvalho, M.; Franco, S. S. O.; Mendonça, R. A Queda Recente da Desigualdade de Renda no Brasil. In: M. N. F. Ricardo Paes De Barros, Gabriel Ulyssea (Ed.). Desigualdade de Renda no Brasil: uma análise da queda recente. Brasília: IPEA, v.1, 2007. A Queda Recente da Desigualdade de Renda no Brasil 
Barros, R. P.; S. Cury; Ulyssea, G. A Desigualdade de Renda no Brasil Encontra-se Subestimada? Uma análise comparativa usando Pnad, POF e Contas Nacionais. In: M. N. F. Ricardo Paes De Barros, Gabriel Ulyssea (Ed.). Desigualdade de Renda no Brasil: uma análise da queda recente. Brasília: IPEA, v.1, 2007. A Desigualdade de Renda no Brasil Encontra-se Subestimada? Uma análise comparativa usando Pnad, POF e Contas Nacionais

Blundell, R.; Gosling, A.; Ichimura, H.; Meghir, C. Changes in the Distribution of Male and Female Wages Accounting for Employment Composition Using Bounds. Econometrica, v.75, n.2, março, p.p. 323-363. 2007.

Bonelli, R.; Ramos, L. Distribuição de Renda no Brasil: Avaliação das Tendências de Longo Prazo e Mudanças na Desigualdade desde Meados dos Anos 70. Revista Brasileira de Economia, v.49, p.pp. 353-73. 1995.

Heckman, J. J. Sample Selection Bias as a Specification Error. Econometrica, v.47, p.p. 153-161. 1979.

Hoffmann, R. A Distribuição de Renda no Brasil no período 1993-1999. Manuscrito não publicado. Unicamp. 2001

Queda da Desigualdade da Distribuição de Renda no Brasil, de 1995 a 2005, e Delimitação dos Relativamente Ricos em 2005. In: M. N. F. Ricardo Paes De Barros, Gabriel Ulyssea (Ed.). Desigualdade de Renda no Brasil: uma análise da queda 
recente. Brasília: IPEA, v.1, 2007. Queda da Desigualdade da Distribuição de Renda no Brasil, de 1995 a 2005, e Delimitação dos Relativamente Ricos em 2005

Instituto de Pesquisa Econômica Aplicada - IPEA. Sobre a recente queda da desigualdade de renda no Brasil. Brasília. 2006. (Nota Técnica).

Langoni, C. G. Distribuição de Renda e Desenvolvimento Econômico no Brasil. Rio de Janeiro. 1973 (Expressão e cultura)

Manski, C. The Selection Problem in Advances In Econometrics, Sixth World Congress Vol 1., Editor C. Sims, Cambridge University Press. 1994

Manski, C. Identification for Prediction and Decision. Cambridge, Harvard University Press, 2007.

Menezes-Filho, N. A. Educação e Desigualdade. In: N. A. Menezes-Filho e M. D. B. Lisboa (Ed.). Microeconomia e Sociedade no Brasil. Rio de Janeiro: Contra Capa, v.1, 2001. Educação e Desigualdade, p.p. 13-50

Neri, M. Desigualdade, Estabilidade e Bem-Estar Social. In: M. N. F. Ricardo Paes De Barros, Gabriel Ulyssea (Ed.). Desigualdade de Renda no Brasil: uma análise da queda recente. Brasília: Instituto de Pesquisa Econômica Aplicada, v.1, 2007. Desigualdade, Estabilidade e Bem-Estar Social 
Osório, R. G.; S. S. D. Soares. Desigualdade e Bem-Estar no Brasil na Década da Estabilidade. In: M. N. F. Ricardo Paes De Barros, Gabriel Ulyssea (Ed.). Desigualdade de Renda no Brasil: uma análise da queda recente. Brasília: IPEA, v.1, 2007. Desigualdade e Bem-Estar no Brasil na Década da Estabilidade

Rosembaum, P., R.; Rubin D. B. The central role of propensity score in observational studies for causal effects. Biometrika, v.70, n.1, p.p. 41-55. 1983.

Salm, C. Sobre a Recente Queda da Desigualdade de Renda no Brasil: uma leitura crítica. In: M. N. F. Ricardo Paes De Barros, Gabriel Ulyssea (Ed.). Desigualdade de Renda no Brasil: uma análise da queda recente. Brasília: IPEA, v.1, 2007. Sobre a Recente Queda da Desigualdade de Renda no Brasil: uma leitura crítica

Soares, S. S. D. Análise de bem-estar e decomposição por fatores da queda na desigualdade entre 1995 e 2004. Revista Econômica, v.8, n.1, p.83-115. 2006.

Tobin, J. Estimation of Relationships for Limited Dependent Variables. Econometrica, v.26, p.p. 24-36. 1956. 